\title{
Characteristics of Future Changes in Summertime East Asian Monthly Precipitation in MRI-AGCM Global Warming Experiments
}

\author{
Tomoaki OSE \\ Meteorological Research Institute, Tsukuba, Japan \\ (Manuscript received 29 August 2018, in final form 19 November 2018)
}

\begin{abstract}
Global warming experiments using three different $60 \mathrm{~km}$ mesh atmospheric global circulation models are studied to characterize ensemble mean future changes in monthly East Asian precipitation for June to August. During the summer, wetting and drying effects due to changes in the mean vertical motion play a key role in future precipitation changes, as does the "wet-get-wetter" effect due to increased moisture. The former processes are related adiabatically to the projected modification of $500 \mathrm{hPa}$ horizontal atmospheric circulation, which is characterized by two cyclonic circulation anomalies extending over the eastern Eurasian Continent $(\mathrm{C} 1)$ and the western North Pacific Ocean (C2) for each month.

Over Japan, the western edge of C2 shifts from a region south of the Japanese Islands to northern Japan during June to August, representing a delayed northward movement or southward shift of the westerly jet over the western North Pacific in the future compared with the present-day climatology. Most regions of Japan lie within the northeasterly wind and associated downward-motion zones of $\mathrm{C} 2$, leading to significant uncertainties in future precipitation over Japan by the offset against the "wet-get-wetter" effect and possibly even a future decrease in precipitation. A wetter future climate is anticipated under weak subsidence or upward vertical motion zone of C2, such as western Japan in August away from C2, and the Southwest Islands of Japan in June in the C2 southwesterly wind zone. Over the eastern Eurasian Continent, C1 is distributed mainly over northeastern China in June and over central and southern China in July and August, respectively. During these months, most of the eastern regions are located within the southwesterly to southeasterly wind zone of $\mathrm{C} 1$, indicating wet future conditions due to enhanced upward motion. This tendency drives a further increase in precipitation in future wetter East Asian climate via the "wet-get-wetter" effect and the increased evaporation.
\end{abstract}

Keywords global warming; East Asia; precipitation; monsoon; MRI-AGCM

Citation Ose, T., 2019: Characteristics of future changes in summertime East Asian monthly precipitation in MRI-AGCM global warming experiments. J. Meteor. Soc. Japan, 97, 317-335, doi:10.2151/jmsj.2019-018.

\section{Introduction}

As it is now widely accepted that global warming impacts not only regional surface temperature but also precipitation, numerous studies have focused on future

Corresponding author: Tomoaki Ose, Meteorological Research Institute, 1-1 Nagamine, Tsukuba, Ibaraki 305-0052, Japan

E-mail: tomoaose@mri-jma.go.jp

J-stage Advance Published Date: 7 December 2018 changes in regional precipitation patterns in East Asia (Kitoh et al. 1997; Kimoto 2005; Kitoh and Uchiyama 2006). The zeroth-order approximation for future precipitation change is described via the "wet-gettingwetter" and "dry-getting-drier" effects (Held and Soden 2006). When precipitation changes are divided into thermodynamic and dynamic effects (e.g., Emori and Brown 2005; Seager et al. 2010), the thermodynamic effect corresponds to the "wet-getting-wetter" and "dry-getting-drier" effects. However, the dynamic 
effect is so significant for regional precipitation that it creates differences among future regional monsoons of the world (Endo and Kitoh 2014). Applying this division of precipitation change over East Asia to the fifth phase of Coupled Model Intercomparison Project (CMIP5) simulations, Zhou et al. (2018) concluded that the thermodynamic component is robust among the models, whereas the dynamic component with the circulation changes contributes considerable uncertainties to projections of the East Asian summer monsoon.

The dynamical components of moisture decomposition share common characteristics among the models, such as the weakening of the tropical circulation in the future (Vecchi and Soden 2007). This is the case for the future summer Asian monsoon. For example, in their analysis of the third phase of CMIP (CMIP3) models, Hirahara et al. (2012) suggested a weakening of summer Asian monsoon circulation and shrink of the Tibetan High by decreased upper tropospheric divergence in the western North Pacific. They also reported a projected strengthening of the southern side of the East Asian jet stream and delayed withdrawal of the Baiu under future climate conditions. The above relationship between the future changes in the jet stream and the Baiu is consistent with the theoretical study of Horinouchi and Hayashi (2017).

The high-resolution Meteorological Research Institute-Atmospheric Global Circulation Model version 3.2, known as MRI-AGCM3.2 (MRI-AGCM3.2H for $60 \mathrm{~km}$ mesh and MRI-AGCM3.2S for $20 \mathrm{~km}$ mesh), simulates high-skill climatology for summer precipitation over East Asia (Kusunoki 2016) in addition to other atmospheric fields (Mizuta et al. 2012). This is a necessary condition for the precise estimation of the "wet-get-wetter" effect pertaining to future climate projections. Consequently, MRI-AGCM3.2 has been employed in conjunction with CMIP-derived and observed sea surface temperature (SST) data to explore the detailed patterns of regional climate under global warming scenarios (Kitoh et al. 2016).

Okada et al. (2017) analyzed global warming experiments using the $20 \mathrm{~km}$ mesh version of MRI-AGCM 3.2 (MRI-AGCM3.2S) to assess seasonal evolution of atmospheric conditions for the Baiu in the future. They showed that the Baiu frontal zone remains south of Japan in June and that the end date of the Baiu depends on the future distribution of SSTs. In a similar study, Kusunoki (2017) summarized a series of global warming simulations undertaken using various versions of MRI-AGCM3.2, SST changes, and emission scenarios. That study reported a pattern of delayed termination or delayed onset of the East Asian rainy season under future climate conditions, depending on the simulations. Ose (2017) analyzed MRI-AGCM global warming experiments to explain the cumulusscheme dependence of future summertime precipitation over East Asia. In that study, which is based on the Baiu rain-band mechanism of Sampe and Xie (2010), the authors concluded that simulated future changes in $500 \mathrm{hPa}$ horizontal atmospheric circulation and associated adiabatic vertical motion are attributable to intermodel differences in precipitation change.

The purpose of this study is to interpret projected future changes in monthly June-to-August precipitation over East Asia and summarize their characteristics, following the work of Ose (2017) for the Juneto-August mean; for each month of the summer, the future changes in summer precipitation are decomposed into the "wet-get-wetter" effect due to increased moisture content and the wet and dry effects caused by changes in atmospheric circulation. Key issues include (1) whether the analytical methodology employed by Ose (2017) and the concept of the Baiu rain-band introduced by Sampe and Xie (2010) are applicable to the monthly analysis, (2) the characteristics and predictability of the projected monthly precipitation changes, and (3) the anticipated changes in monthly atmospheric circulation associated with question (2). The results related to points (2) and (3) are potentially valuable for interpreting the output of other global warming simulations. The remainder of this manuscript is organized as follows. Details of the analytical methods are given in Section 2, and the results are given in Section 3. Sections 4 and 5 provide the discussion and summary, respectively.

\section{Experimental data for analysis}

In the present study, global warming experiments under the Representative Concentration Pathways (RCP) scenario 8.5 (IPCC 2013) using three different versions of MRI-AGCM3.2H (60 km mesh) (see Table 1d of Kitoh et al. 2016) were analyzed, acknowledging that this grid size is marginal in terms of representing the Japanese Archipelago. Three different versions of MRI-AGCM3.2H were adopted for a three-model ensemble of global warming simulations and are referred to here as the YS, KF, and AS models, for which cumulus schemes of YS, KF, and AS are incorporated, respectively. Specifically, the YS (or YoShimura cumulus) scheme is that presented by Yoshimura et al. (2015), following Tiedtke (1989), and the KF scheme is based on Kain and Fritsch (1990), whereas the AS scheme is that introduced by the prog- 
nostic Arakawa-Schubert model (Pan and Randall 1998) but modified in 2007 by the Japan Meteorological Agency. Although the statistical significance and the reliability of the models are not focused on in this study, the three-model ensemble is needed to confirm the qualitative commonness and diversity of results among the models.

The global warming experiments consist of two 25 -year time-slice experiments. The first comprises a present-day simulation for the 25 -year period from 1980 to 2004 under observed monthly SST data, whereas the second considers the period from 2075 to 2099, for which the CMIP5-derived future SST change and trend (Mizuta et al. 2014) have been added to the present-day observed monthly SST. Consequently, the term "future change" is defined here as the difference between 2075-2099 and 1980-2004 mean values, whereas the term "climatology" refers to the 25-year mean. Although the results are dependent to some degree on the prescribed future SST changes (e.g., Endo et al. 2012; Kusunoki 2017; Okada et al. 2017), the present study concerns the three-model ensemble experiments using the CMIP5 ensemble mean SST. The Global Precipitation Climatology Project (GPCP) (Adler et al. 2003) and the Japanese 55-year Reanalysis (JRA-55 reanalysis) (Kobayashi et al. 2015) are used for the comparison of precipitation and atmospheric elements between the simulated and the observed present-day climatology.

\section{Results}

\subsection{Three-model ensemble mean of future precipitation change}

a. Decomposition into the "wet-get-wetter" effect and the circulation change effect

Figure 1 depicts the three-model ensemble mean of present-day precipitation for (a) June-July-August (JJA) mean, (b) June, (c) July, and (d) August, together with their corresponding GPCP observations. The present-day precipitation climatology is important not only for confirming the model performance of the present-day simulation, but also for estimating the "wet-get-wetter" effect in future change. The distribution of simulated JJA precipitation is comparable to the observation data, although the northward extension of precipitation exceeding $4 \mathrm{~mm}^{-1}{ }^{-1}$ is relatively weak. The three-model ensemble also reconstructs the seasonal evolution of precipitation in the GPCP dataset; precipitation exceeding $8 \mathrm{~mm}$ day $^{-1}$ features the Meiyu over southern China in June, the Baiu over Japan in June and July, and the Changma over Korea during July and August. Simulated August precipitation appears to be concentrated over the Japanese Archipelago, whereas relatively dry areas $\left(<2 \mathrm{~mm} \mathrm{day}^{-1}\right)$ are reproduced in the continental interior.

Figure 2 shows the projected changes in precipitation and precipitation minus evaporation in the threemodel mean. Table 1 lists the principal areas in Japan where the changes in monthly precipitation are projected and the consistency among the three models. While the distribution and seasonal progress of future precipitation change over Japan are not simple, most eastern continental regions exhibit a significant increase in precipitation for most months. Exceptions include interior regions through the summer, parts of southern China in July, and eastern Korea in August. It is noted that the future increase in evaporation contributes to that in precipitation by around 0.5 $\mathrm{mm}$ day $^{-1}$ even over East Asia.

Equation (1) is a simplified moisture budget for future change in precipitation minus evaporation, following Eq. (2) of Ose (2017):

$$
d P-d E \approx\left(-\frac{2}{\pi g}\right) \times(q s \cdot d \omega 500+d q s \cdot \omega 500),
$$

where $\omega 500$ and $q s$ are the vertical velocity at $500 \mathrm{hPa}$ in pressure coordinates and the surface specific humidity, respectively. The terms $d \omega 500$ and $d q s$ represent the future changes in $\omega 500$ and $q s$, while $d P$ and $d E$ are the future changes in precipitation and evaporation, respectively, and $g$ is the gravity constant. According to Ose (2017), this equation represents a good approximation of the anticipated changes in precipitation minus evaporation over East Asia in the MRI-AGCM $3.2 \mathrm{H}$ global warming simulations. Figure 3 shows both the right-hand and the left-hand sides of Eq. (1). The similarities between the shading and contours for each month are consistent with the data in Table 1.

Figure 4 depicts the first term on the right-hand side of Eq. (1):

$$
\left(-\frac{2}{\pi g}\right) \times(q s \cdot d \omega 500)
$$

which represents the precipitation change associated with the future circulation change ( $d \omega 500)$. Compared with the right-hand side of Eq. (1) (Fig. 3), the decrease in precipitation or dry tendency due to downward motion is more intensified in Eq. (2) (Fig. 4), although similarities between the two outputs can be found for the Southwest Islands of Japan during June and July and for parts of northern Japan in July. 
(a) $\operatorname{pr}(\mathrm{mm} /$ day $)$ JJA 3 model mean \& gpcp

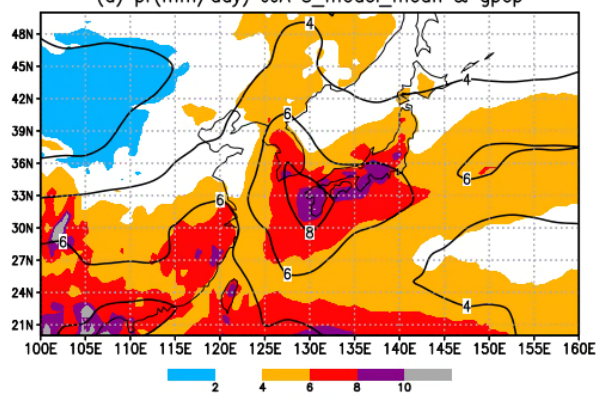

(c) $\mathrm{pr}(\mathrm{mm} /$ day) JUL 3_model_mean \& gpcp

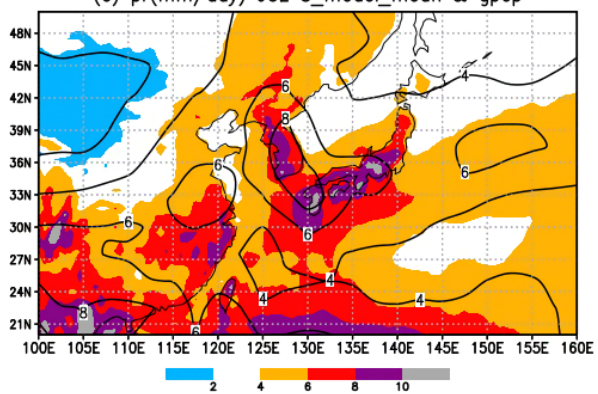

(b) $\operatorname{pr}(\mathrm{mm} /$ day) JUN 3 model mean \& gpcp

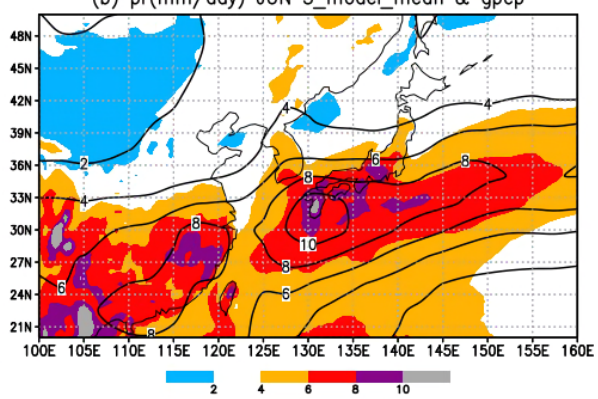

(d) $\mathrm{pr}(\mathrm{mm} /$ day) AUG 3_model_mean \& gpcp

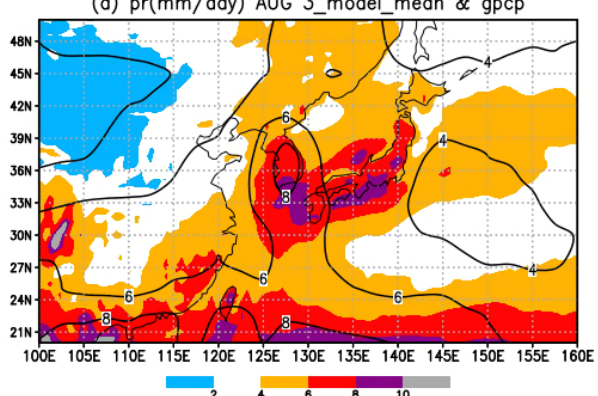

Fig. 1. Present-day precipitation climatology over East Asia during the 25-year period from 1980 to 2004 . The figure shows the three-model ensemble mean (shading) and GPCP observed values (contours) for (a) the JJA average, (b) June, (c) July, and (d) August in $\mathrm{mm} \mathrm{day}^{-1}$. Contours are only for 2, 4, 6, 8 and $10 \mathrm{~mm}$ day $^{-1}$.

(a) $\mathrm{dpr} \& \mathrm{dpr}-\operatorname{devp}(\mathrm{mm} /$ day) JJA 3 model mean

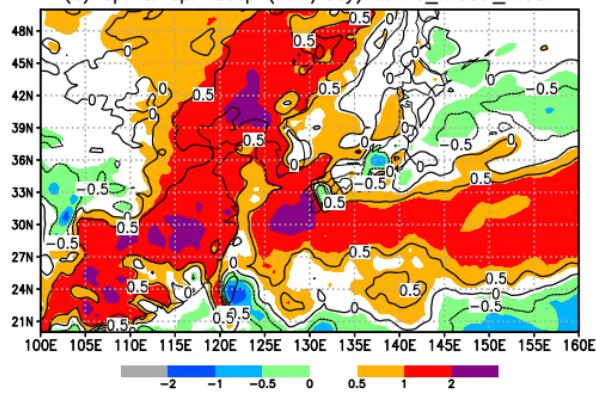

(c) dpr \& dpr-devp (mm/day) JUL 3 model mean

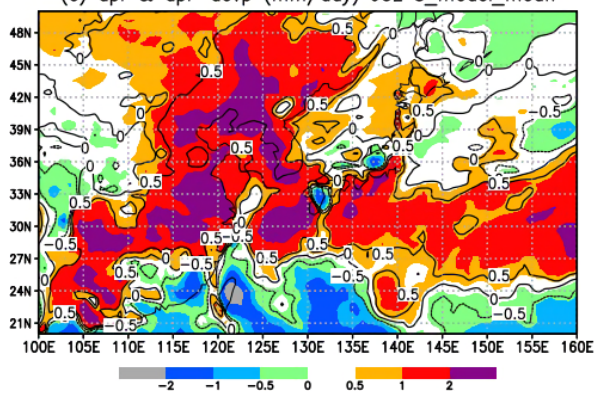

(b) dpr \& dpr-devp (mm/day) JUN 3 model mean

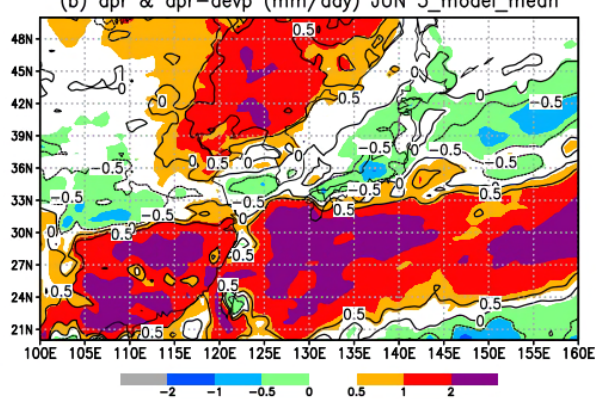

(d) $\mathrm{dpr} \& \mathrm{dpr}$-devp (mm/day) AUG 3 model mean

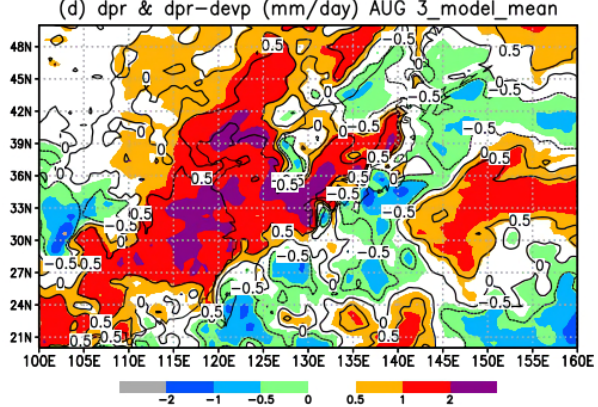

Fig. 2. Simulated changes in the three-model ensemble mean precipitation (shading) and precipitation-minusevaporation (contours) from the period 1980-2004 to 2075-2099 for (a) the JJA average, (b) June, (c) July, and (d) August. All values are in $\mathrm{mm} \mathrm{day}^{-1}$. Contours are only for $-0.5,0.0$ and $0.5 \mathrm{~mm}^{\text {day }}{ }^{-1}$. 
Table 1. Principal areas of Japan where increased and decreased monthly precipitation are detected by the threemodel ensemble mean, as shown in Fig. 2. The bold letters depict the areas for which there is a consistency among the model simulations, judged based on Figs. 9a, 10a, and $12 \mathrm{a}$.

\begin{tabular}{|c|c|c|}
\hline Month & $\begin{array}{c}\text { Increased } \\
\text { precipitation area }\end{array}$ & $\begin{array}{c}\text { Decreased } \\
\text { precipitation area }\end{array}$ \\
\hline June & $\begin{array}{l}\text { (1) southern Japan } \\
\text { including South- } \\
\text { west Islands }\end{array}$ & (1) central Japan \\
\hline July & $\begin{array}{l}\text { (1) Southwest Islands } \\
\text { (2) northern Japan } \\
\text { (3) western Japan } \\
\text { (4) Pacific Ocean side }\end{array}$ & (1) central Japan partly \\
\hline August & $\begin{array}{l}\text { (1) western Japan } \\
\text { (2) Japan Sea side }\end{array}$ & $\begin{array}{l}\text { (1) Pacific Ocean side } \\
\text { partly }\end{array}$ \\
\hline
\end{tabular}

Conversely, enhanced wet anomalies, due to enhanced upward motion, are evident throughout the summer months for most eastern regions of the Eurasian Continent, with the exception of central China in June and southern China and eastern Korea in July and August. Over the eastern regions of the Eurasian Continent, Eq. (2) in Fig. 4 is consistent with the qualitative features of precipitation change (Figs. 2, 3).

\section{b. Changes in atmospheric circulation}

Figure 5 shows the projected future changes in vertical pressure-velocity at $500 \mathrm{hPa}$ that is estimated adiabatically according to the thermodynamical calculation at 6-hour intervals based on Eq. (3) for $d \omega 500$ 6Hdiag, together with simulated changes in the $500 \mathrm{hPa}$ stream function.

$$
\begin{aligned}
& d \omega 500 \_6 H d i a g \\
&=\left\{\left[\sum_{\text {Future }}-\vec{v} \cdot \operatorname{grad}(s)\right]-\left[\sum_{\begin{array}{c}
\text { Present } \\
\text { day }
\end{array}}-\vec{v} \cdot \operatorname{grad}(s)\right]\right\} \\
& /\left[\sum_{\substack{\text { Present } \\
\text { day }}}\left(\frac{\partial s}{\partial p}\right)\right],
\end{aligned}
$$

where $\vec{v}$ and $s$ are the horizontal wind vector and dry static energy, respectively. The vertical derivative of $s$ is calculated between 200 and $850 \mathrm{hPa}$.

The diagnostically estimated $d \omega 5006$ Hdiag is less than approximately half the magnitude of $d \omega 500$ (not (a) $q * d w 500+w 500 * d q ~ \& ~ d p r-\operatorname{devp}(\mathrm{mm} /$ day) JJA

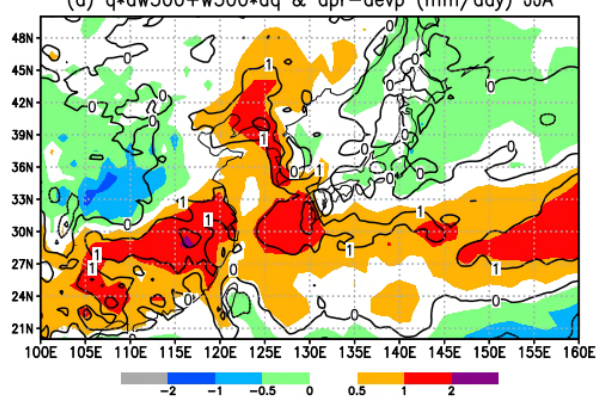

(c) $q * d w 500+w 500 * d q \& d p r-\operatorname{devp}(\mathrm{mm} /$ day) JUL

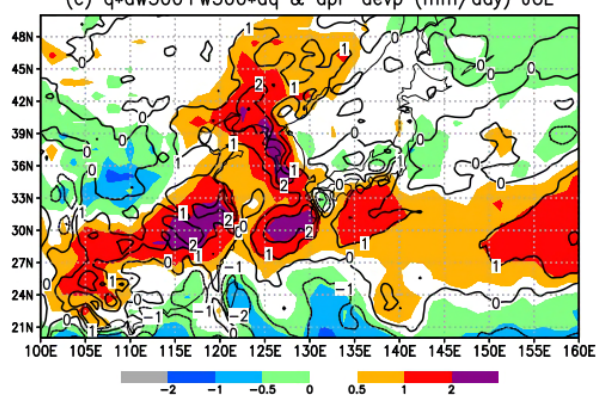

(b) q*dw500+w500*dq \& dpr-devp (mm/day) JUN

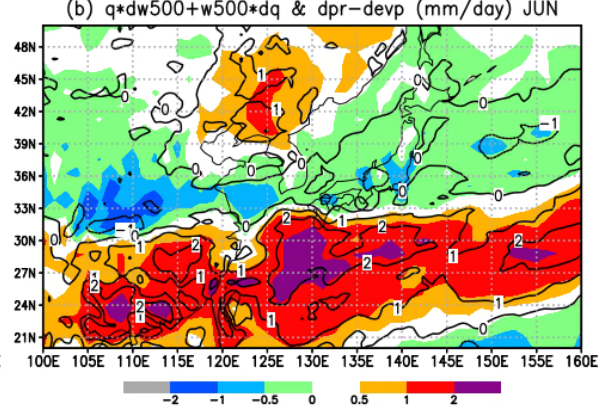

(d) $q * d w 500+w 500 * d q \& d p r-\operatorname{devp}(\mathrm{mm} /$ day) AUG

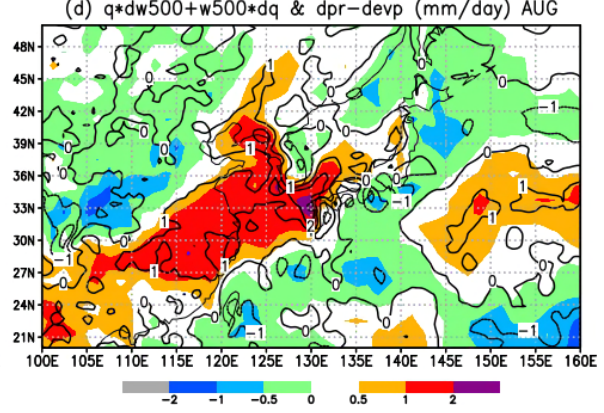

Fig. 3. Projected future changes in the three-model ensemble mean precipitation minus evaporation (contours) and the right-hand side of Eq. (1) (shading). Values are shown for (a) the JJA average, (b) June, (c) July, and (d) August in $\mathrm{mm}_{\text {day }}{ }^{-1}$. Contours are for $-2.0,-1.0,0.0,1.0$, and $2.0 \mathrm{~mm}^{\text {day }^{-1}}$. 
(a) q*dw500 \& dpr-devp (mm/day) JJA

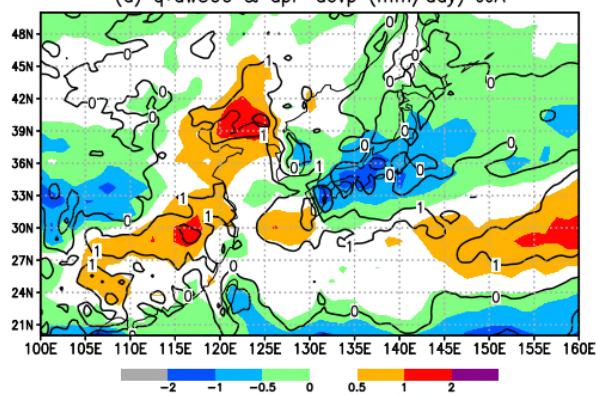

(c) q*dw500 \& dpr-devp (mm/day) JUL

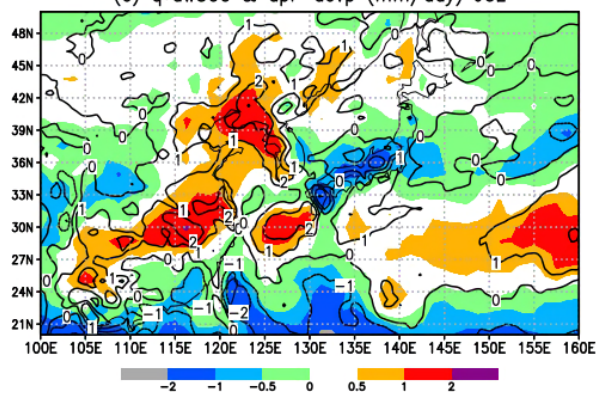

(b) q*dw500 \& dpr-devp (mm/day) JUN

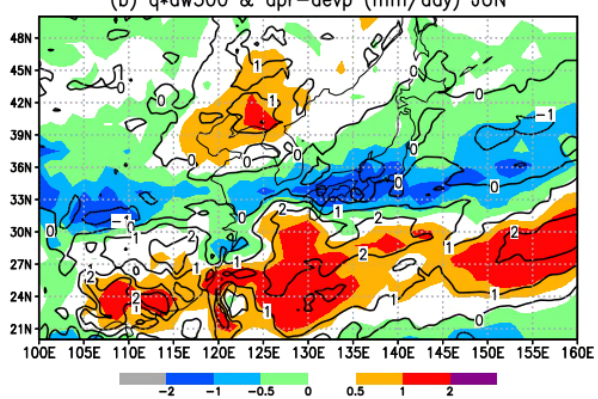

(d) q*dw500 \& dpr-devp (mm/day) AUG

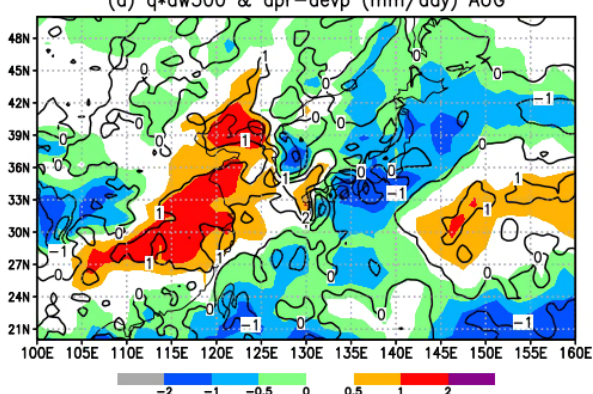

Fig. 4. Same as Fig. 3 but with Eq. (2) represented by shading.

(a) dpsi500(m2/s) \& dw500_6Hdiag_constS(hPa/h) JJA

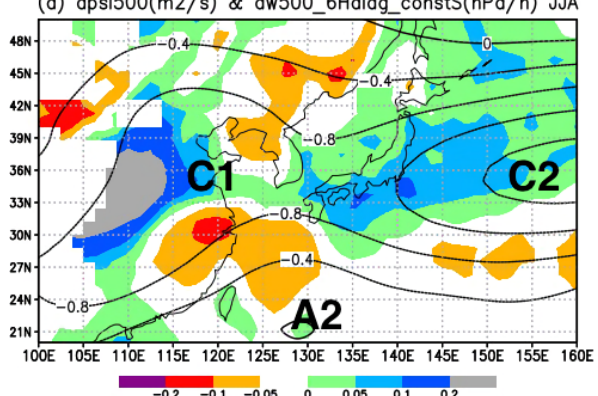

(c) dpsi500(m2/s) \& dw500_6Hdiag_constS(hPa/h) JUL

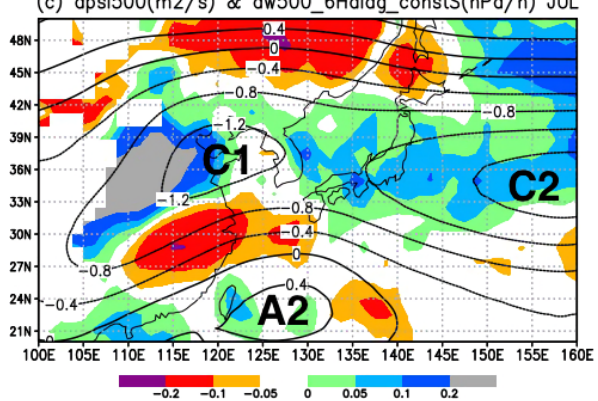

(b) dpsi500(m2/s) \& dw500 6Hdiag constS(hPa/h) JUN

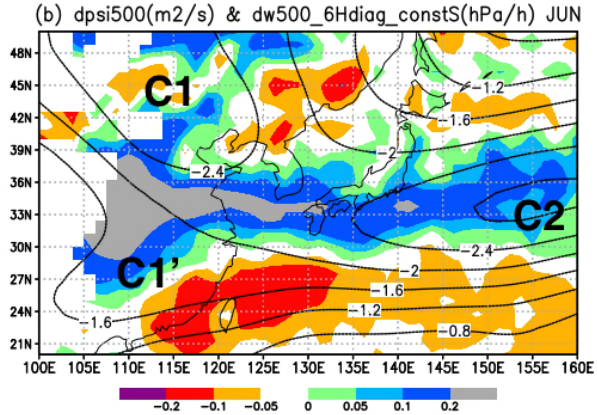

(d) dpsi500(m2/s) \& dw500_6Hdiag_constS(hPa/h) AUG

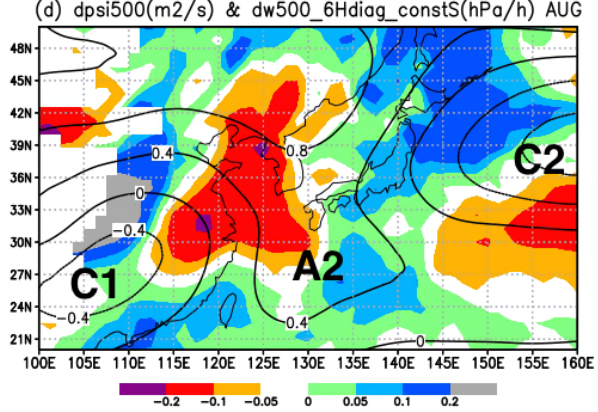

Fig. 5. Projected future changes in the three-model ensemble mean of the stream function at $500 \mathrm{hPa}\left(10^{6} \mathrm{~m}^{2} \mathrm{~s}^{-1}\right)$ (contours). $\mathrm{C} 1, \mathrm{Cl}^{\prime}$, and $\mathrm{C} 2$ denote cyclonic circulation anomalies, whereas $\mathrm{A} 2$ represents anticyclonic circulation anomalies. The shading depicts vertical velocity changes in the pressure coordinate $\left(\mathrm{hPa} \mathrm{h}^{-1}\right)$ during the 25 -year period, estimated adiabatically from Eq. (3) for 6-hour intervals. The values shown are for (a) the JJA average, (b) June, (c) July, and (d) August. 
(a) dpsi500 \& dw500 1Mmean diag constS JJA

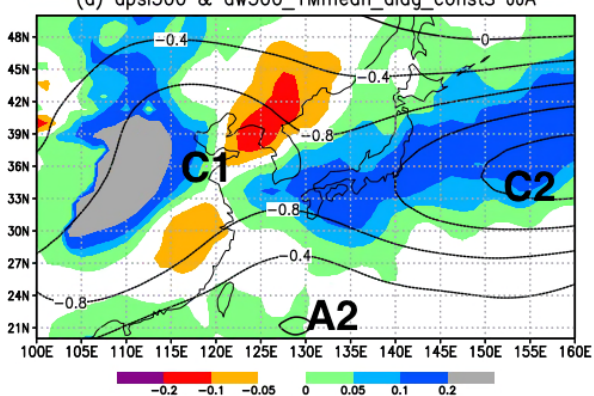

(c) dpsi500 \& dw500 1Mmean diag constS JUL

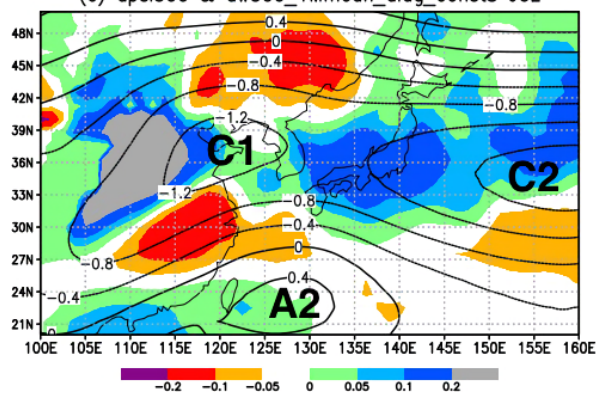

(b) dpsi500 \& dw500 1Mmean diag constS JUN

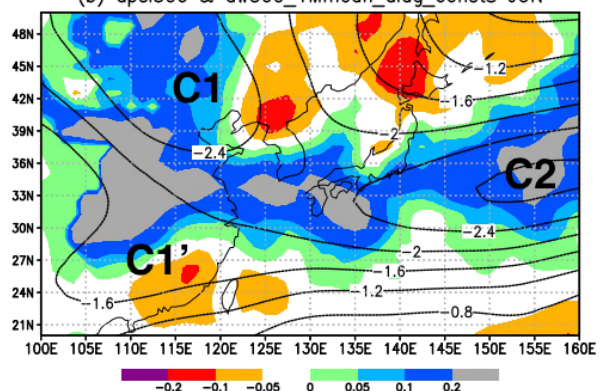

(d) dpsi500 \& dw500_1Mmean_diag_constS AUG

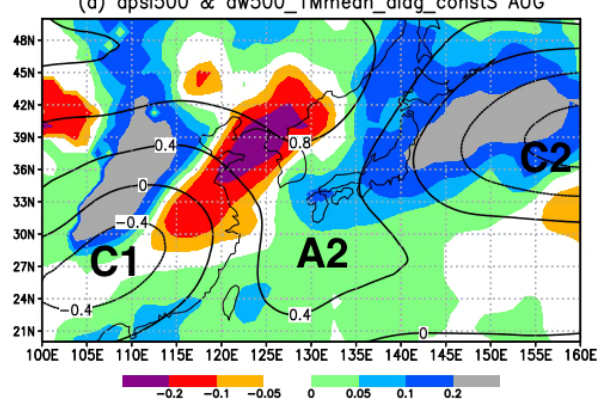

Fig. 6. Same as Fig. 5 but with shading representing projected future changes in vertical velocity, estimated adiabatically from the 25-year monthly average.

shown), as reported by Sampe and Xie (2010) and illustrated by Ose (2017). Aside from the magnitude, a comparison of Figs. 4 and 5 reveals that both the distribution of $d \omega 500$ 6 Hdiag and its seasonal change from June to August capture the first-order features exhibited by $d \omega 500$. Figure 6 depicts $d \omega 500 \_1$ Mmean diag, which is estimated in the same way as $d \omega 500_{-}^{-}$ 6 Hdiag but using 25 -year mean monthly fields. The resulting distribution of d $\omega 5001$ Mmean diag is characteristically similar to that of $\bar{d} \omega 500 \_6 \bar{H}$ diag.

The current assessment revealed that $d \omega 500$ 6 Hdiag and d 1500 1Mmean_diag are consistent with the projected future changes in the 25-year average monthly mean $500 \mathrm{hPa}$ stream function, as indicated by contours in Figs. 5 and 6. Roughly, southerly and northerly winds tend to correspond to adiabatic upward and downward motion, respectively (Ose 2017). Assuming that these modifications of atmospheric circulation over East Asia are driven remotely by wave propagation or the Asia-Pacific monsoon system, future precipitation changes due to $d \omega 500$ (Fig. 4) can be attributed to changes in adiabatic vertical motion,

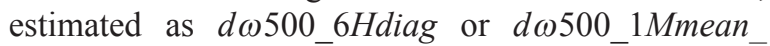
diag.

In Figs. 5 and 6, the terms " $\mathrm{A}$ " and " $\mathrm{C}$ " represent major anticyclonic and cyclonic circulation anomalies, respectively, in the future relative to the present-day climatology. These terms, including numbered Cs and As, such as $\mathrm{C} 1$ and $\mathrm{A} 1$ for each month, are used hereafter in the paper. Specifically, C1 corresponds to the southward shift of westerly winds in the eastern continental areas, and $\mathrm{C} 2$ reflects the equatorward shift of the jet stream in the western North Pacific (see Section 4). In terms of influence, $\mathrm{C} 1$ and $\mathrm{C} 2$ are significant factors in future precipitation patterns over the eastern Eurasian Continent and the Japanese Archipelago, respectively. For instance, the north-south elongation of $\mathrm{C} 1$ over the eastern continent results in the occurrence of upward air motion, related to the southerly air flow of $\mathrm{C} 1$ over the continent's coastal margin. Specifically, this effect impacts an area stretching from northeastern to central and southern China and Korea for much of the summer.

$\mathrm{C} 2$ exhibits an east-west orientation with downward motion over its northern and western sectors corresponding broadly to the Japanese region. During June, C2 extends longitudinally from the western North Pacific to an area south of Japan, with the effect that western and eastern parts of the Japanese Archipelago are largely dominated by predominant descending air. In contrast, upward motion occurs over the sea to the south of Japan. In July, the northward-shifted western 
edge of C2 spreads over the Japanese Archipelago, resulting in a relatively weak downward motion over most parts of the archipelago, with the exception of some ascending motion in parts of northern and southern Japan. When the western edge of $\mathrm{C} 2$ migrates north of Japan during August, the archipelago experiences a descending air flow.

While $\mathrm{C} 1$ is distributed over the eastern Eurasian Continent through the summer, its latitudinal location changes from its northerly position in June to a more central region in July and a southern locus in August. Southerly winds of $\mathrm{C} 1$ indicative of ascending air flow are projected from northeastern China to northern Japan during June and July. Northerly winds of C1 dominate over northern China during June and July. An additional zone of southerly wind flow anomalies occurs between $\mathrm{C} 1$ (or $\mathrm{C1}^{\prime}$ ) and $\mathrm{A} 2$, shifting from southern China in June to central China in July and from northern China to Korea during August. In summary, the seasonal changes in d 10500 6Hdiag in Fig. 5 and $d \omega 500$ 1Mmean_diag in Fig. 6 can be understood on the basis of future circulation changes such as $\mathrm{C} 1, \mathrm{C}^{\prime}, \mathrm{C} 2$, and $\mathrm{A} 2$, which characterize $d \omega 500$ and contribute to the future precipitation change during June to August. c. Explanation of projected changes in three-modelmean precipitation

A further term for the right-hand side of Eq. (1) is

$$
\left(-\frac{2}{\pi g}\right) \times(d q s \cdot \omega 500)
$$

which represents the "wet-get-wetter" effect depicted in Fig. 7, which has similar patterns to the present-day vertical motion $(\omega 500)$ and precipitation: the wetter effect stretching from central China to western Japan in June (Meiyu and Baiu) and its expansion into eastern Japan and Korea from July (Baiu and Changma) to August. The drier effect is found in northern China, especially in August.

Figure 8 shows the projected precipitation changes according to the three-model ensemble, as in Fig. 2, but in relation to future changes in $500 \mathrm{hPa}$ stream functions. A comparison of Figs. 7 and 8 enables the future precipitation regions of Table 1 to be sorted into those in Table 2, considering contributions from the "wet-get-wetter" effect and changes in atmospheric circulation. For June, the present-day precipitation (Baiu) region of Japan becomes dominated by a drying effect due to descending air flow around $\mathrm{C} 2$. Consequently, the simulations project suppressed precipitation over central Japan and enhanced rainfall over
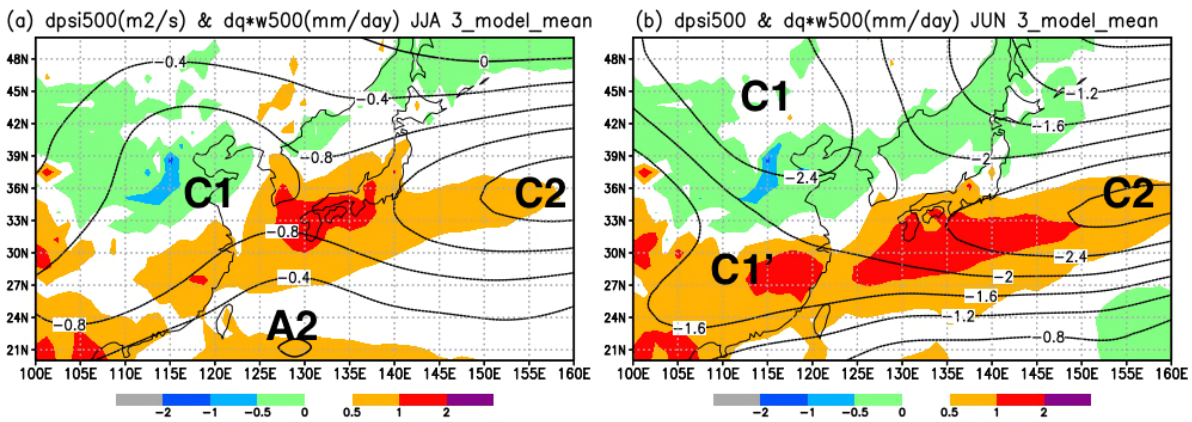

(c) dpsi500 \& dq*w500(mm/day) JUL 3_model_mean

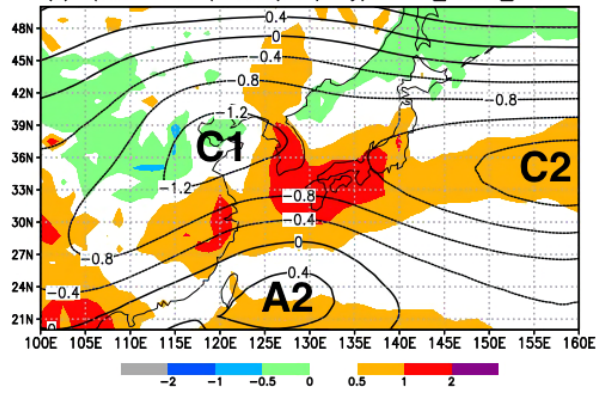

(d) dpsi500 \& dq*w500(mm/day) AUG 3_model_mean

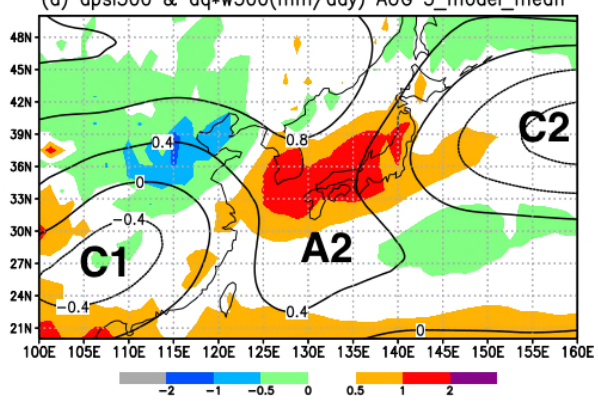

Fig. 7. Same as Fig. 5 but with Eq. (4) represented by shading. 
southern Japan, including the Southwest Islands, as a consequence of upward motion south of $\mathrm{C} 2$.

During July, while C2 and its associated downward moving air flow shift northward, the Pacific side of eastern Japan tends to become wetter. C1 is located at a latitude similar to that of $\mathrm{C} 2$, and the ascending air flow zone of $\mathrm{C} 1$ spreads over northern Japan and the East China Sea. These changes serve to enhance precipitation in northern Japan and over the Southwest Islands. During August, a descending air flow associated with $\mathrm{C} 2$ occurs in a north-south, rather than an east-west direction, leading to drier conditions in the Pacific side of eastern Japan. As C1 distributes in the coastal regions of the continent and $\mathrm{A} 2$ develops between $\mathrm{C} 1$ and $\mathrm{C} 2$, the "wet-get-wetter" effect works effectively away from $\mathrm{C} 1$ and $\mathrm{C} 2$ domains, bringing enhanced precipitation to western Japan and the Japan Sea side.

In contrast to Japan, future precipitation change is stable throughout the summer months over the continental East Asia. While the "dry-get-drier" effect is comparable in magnitude to increased evaporation
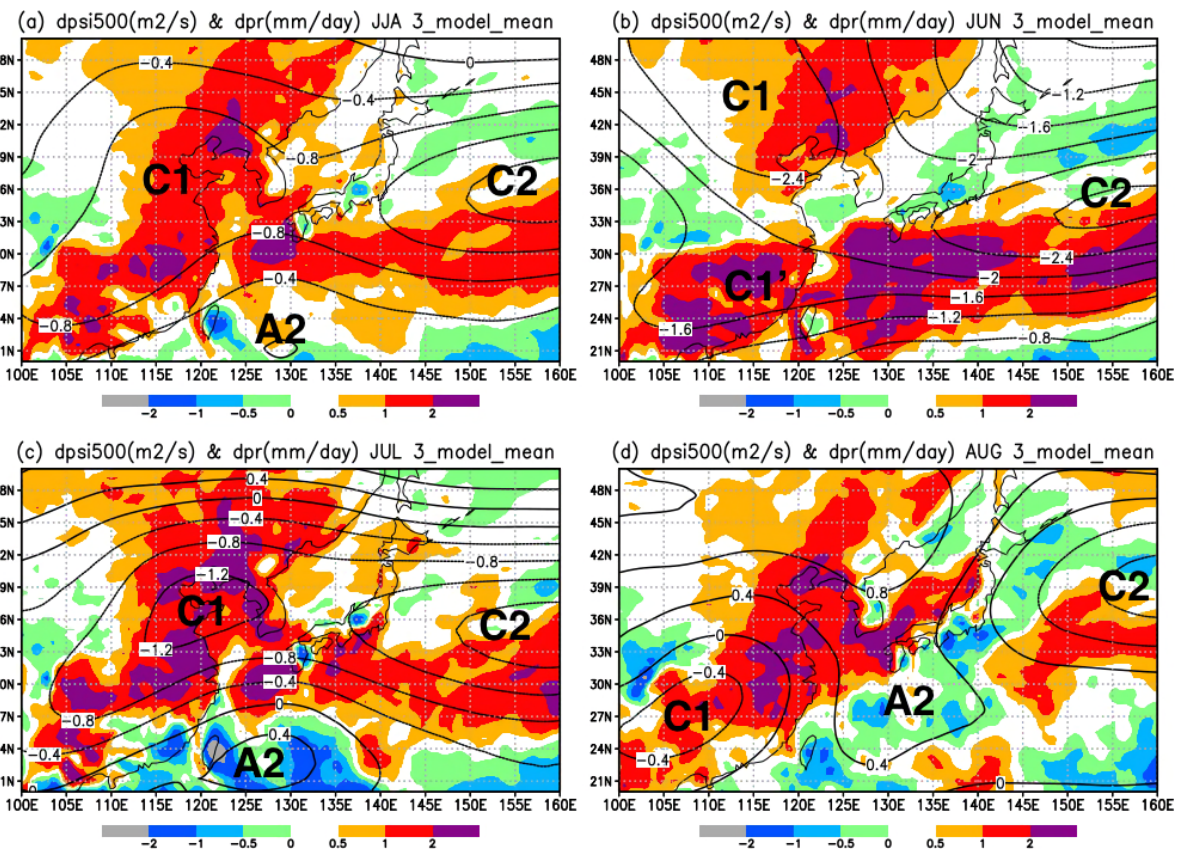

Fig. 8. Same as Fig. 5 but with future changes in the three-model ensemble mean precipitation $\left(\mathrm{mm}^{-1}{ }^{-1}\right)$ represented by shading. Values are shown for (a) the JJA average, (b) June, (c) July, and (d) August.

Table 2. Classifications of the areas listed in Table 1, based on contributions from the "wet-get-wetter" effect and circulation changes. The bold letters are as in Table 1.

\begin{tabular}{|c|c|c|c|c|}
\hline Month & $\begin{array}{c}\text { Increase by } \\
\text { wet-get-wetter effect }\end{array}$ & $\begin{array}{l}\text { Increase by } \\
\text { circulation change }\end{array}$ & $\begin{array}{c}\text { Decrease by } \\
\text { dry-get-drier effect }\end{array}$ & $\begin{array}{l}\text { Decrease by } \\
\text { circulation change }\end{array}$ \\
\hline June & $\begin{array}{l}\text { (1) southern Japan including } \\
\text { Southwest Islands }\end{array}$ & (1) Southwest Islands & & (1) central Japan \\
\hline July & $\begin{array}{l}\text { (1) Southwestern Islands } \\
\text { (2) northern Japan } \\
\text { (3) western Japan } \\
\text { (4) Pacific Ocean side }\end{array}$ & $\begin{array}{l}\text { (1) Southwest Islands } \\
\text { (2) northern Japan partly }\end{array}$ & & (1) central Japan partly \\
\hline August & $\begin{array}{l}\text { (1) western Japan } \\
\text { (2) Japan Sea side }\end{array}$ & & & $\begin{array}{l}\text { (1) Pacific Ocean side } \\
\text { partly }\end{array}$ \\
\hline
\end{tabular}


of about $0.5 \mathrm{~mm} \mathrm{day}^{-1}$, the $\mathrm{C} 1$-induced wet effect is added to the "wet-get-wetter" effect in the eastern continental regions. After all, precipitation is projected to increase significantly for all sectors of continental East Asia, with notable exceptions being interior regions through the summer and parts of southern China in July and eastern Korea during August.

\subsection{Differences in future precipitation changes among the three models}

Figure 9 shows projected changes in precipitation and $500 \mathrm{hPa}$ circulation for the month of June for the three-model mean and YS, KF, and AS simulations. Note that the shading in Fig. 9a represents a complete agreement among the three models with respect to the sign of precipitation change, specifically suggesting by the yellow and blue shadings that all three models indicate positive and negative changes, respectively. While the future changes in precipitation and circulation are model-dependent, the key features depicted in Fig. 8b, such as the existence of $\mathrm{C} 1$ and $\mathrm{C} 2$, are confirmed for each model in Figs. $9 b-d$. There is a close agreement, for instance, on the simulated in- crease in precipitation over southern Japan including the Southwest Islands, which is driven by the upward motion south of $\mathrm{C} 2$ (or C1), combined with the "wetget-wetter" effect.

The principal qualitative difference occurs in the KF simulation (Fig. 9c), in which C2 is shifted away from Japan. Consequently, the associated downward motion and the resulting drying effect do not extend to the Japanese Archipelago. It is indicated in Fig. 9a that the three-model agreement on the future decrease in precipitation over Japan is spotty and that its signal is quantitatively weak.

Figure 10 compares the projections among the three models for July, revealing significant inconsistencies over most of Japan, with the exception of some northern sectors and the Pacific margin. The qualitative difference is attributed to the YS model (Fig. 10b), in which a measurable decrease in precipitation south of Japan conflicts with projections of the other two models as well as the three-model mean. This contrast originates from $\mathrm{C} 2$ being located at a lower latitude in the YS model than in the KF and AS models, which results in drier and wetter future in central and north-

(a) dpsi500(m2/s) \& dpr(mm/day) JUN 3_model_consistency

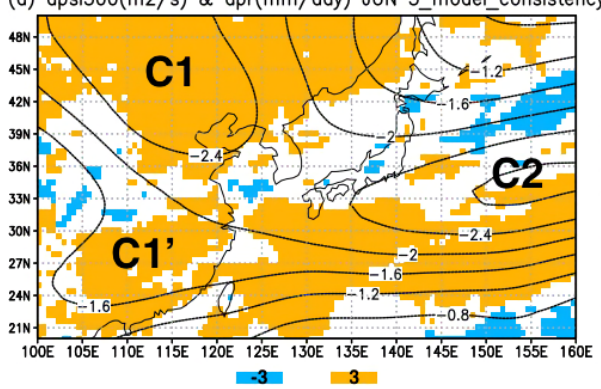

(b) dpsi500 \& dpr(mm/day) JUN HFA_rcp85-HPA

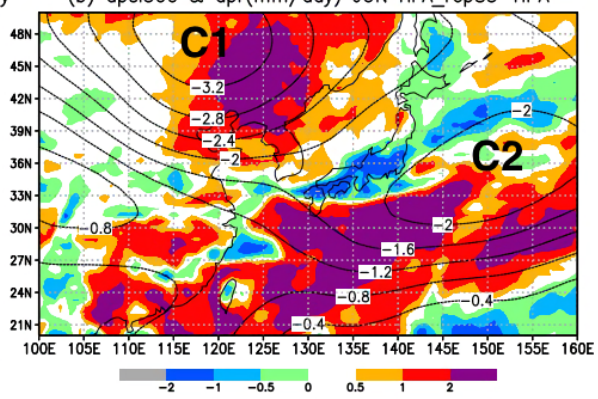

(c) dpsi500 \& dpr(mm/day) JUN HFA_kf_rcp85-HPA_kf
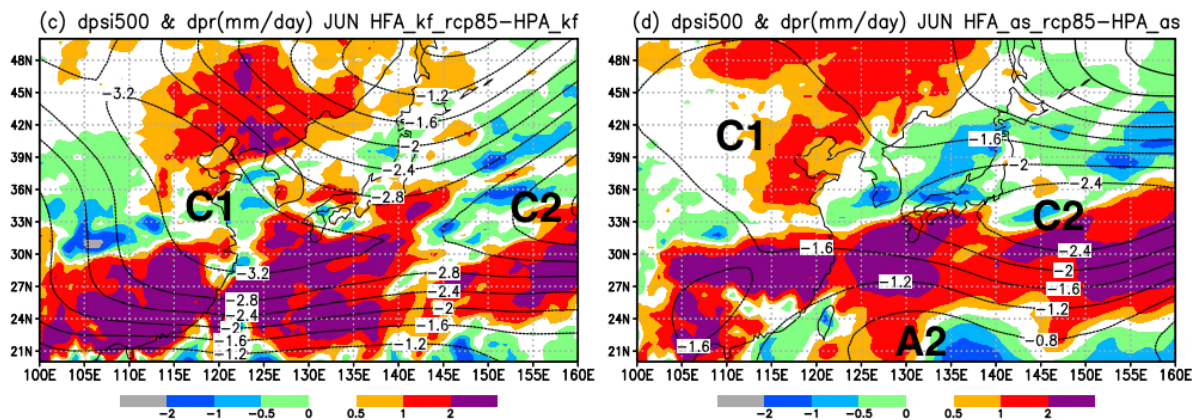

Fig. 9. Projected future changes in the stream function at $500 \mathrm{hPa}\left(10^{6} \mathrm{~m}^{2} \mathrm{~s}^{-1}\right)$ for the month of June (contours). $\mathrm{C} 1, \mathrm{C} 1$ ', and $\mathrm{C} 2$ denote cyclonic circulation anomalies, whereas A2 represents anticyclonic circulation anomalies. Future changes in June precipitation $\left(\mathrm{mm} \mathrm{day}^{-1}\right.$ ) are depicted by shading. Values are shown for the (a) three-model ensemble mean, (b) YS model, (c) KF model, and (d) AS model. The shading in (a) represents an agreement among the three models. Specifically, the yellow/blue shading indicates that future increases/decreases in precipitation are projected commonly by all of the three models. 
ern Japan of the YS model, respectively.

To evaluate the origins of this discrepancy further, simulated changes in horizontal and vertical circulation at $500 \mathrm{hPa}$ are compared among the YS, KF, and AS models and the three-model mean for the AsiaPacific region (Fig. 11). The terms A0 and A1 indicate anticyclonic circulation anomalies in north of Japan and over South Asia, respectively, in addition to the cyclonic circulation anomalies of $\mathrm{C} 1$ and $\mathrm{C} 2$ and the anticyclonic circulation anomaly of A2. The relatively low latitude of $\mathrm{C} 2$ in the YS simulations might be explained by the following differences among the models. One possibility is that the $\mathrm{C} 2$ displacement in YS potentially results from the similarly lowerlatitude position of $\mathrm{A} 0$ in that model, assuming that A0 is driven by wave propagation and/or boundary conditions such as land-sea thermal contrast (Wang and Yasunari 1994; Kamae et al. 2014). Another possibility stems from the notion that the distribution of YS-projected changes in vertical motion over the Pacific is significantly different from those predicted by the KF and AS models. As reported by Endo (2012), CMIP3-projected changes in East Asian circulation are related to the response of the tropical (Walker) circulation to global warming. While the KF and AS simulations produce downward motion from just north of the equator to the latitudes beyond $20^{\circ} \mathrm{N}$, the corresponding one for YS simulation has a more limited latitudinal range lower than $20^{\circ} \mathrm{N}$. The YS, KF, and AS convection schemes may respond differently to a given SST forcing and vertically stabilized future atmospheres.

Figure 12 is the same as Figs. 9 and 10 except for the month of August. All the three models exhibit $\mathrm{C} 1$ and $\mathrm{C} 2$ configurations comparable to the three-model mean (Fig. 8d), with $\mathrm{C} 1$ and $\mathrm{C} 2$ separated by $\mathrm{A} 2$. Therefore, the "wet-get-wetter" effect dominates in western Japan and over the Japan Sea margin during August, where future precipitation increases are broadly consistent. However, the relatively northerly locus of $\mathrm{C} 2$ in the KF scheme appears to weaken the drying effect on Japan's Pacific margin, resulting in an uncertainty of future precipitation estimates (Fig. 12a).

While the pronounced increase in summertime precipitation over the East Asian continent is a robust feature of all three models (see Figs. 9a, 10a, 12a), there remains a significant disagreement about precipitation changes over Japan. This discrepancy is attributed to the results of the previous analysis: while the "wet-get-wetter" effect and the effects of circulation change are consistent over the eastern continental regions, both the effects tend to be opposite over Japan.

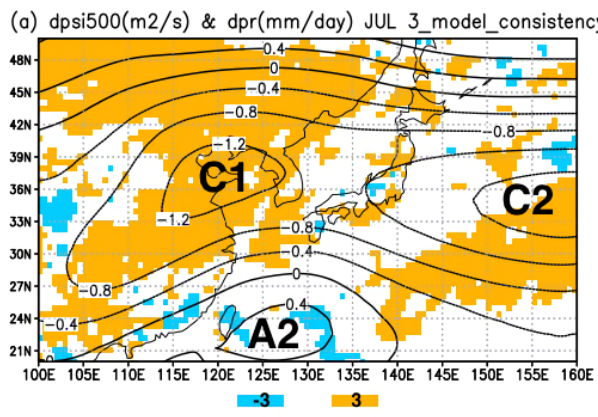

(b) dpsi500 \& dpr(mm/day) JUL HFA_rcp85-HPA

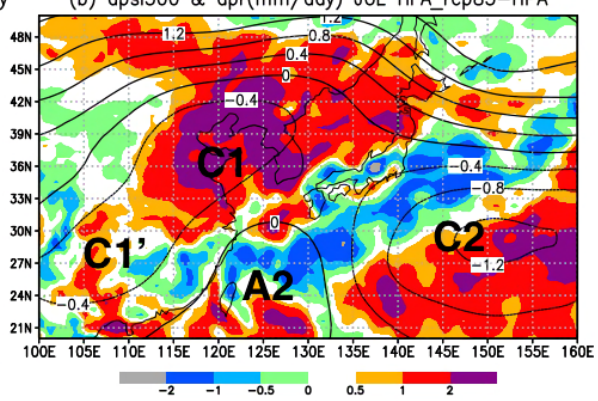

(c) dpsi500 \& dpr(mm/day) JUL HFA kf rcp85-HPA kf
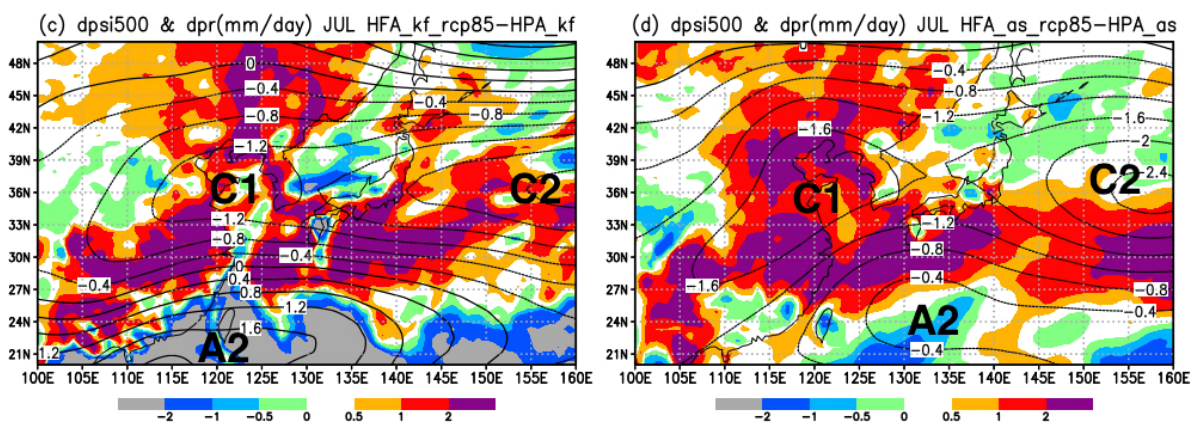

Fig. 10. Same as Fig. 9 but for July. 


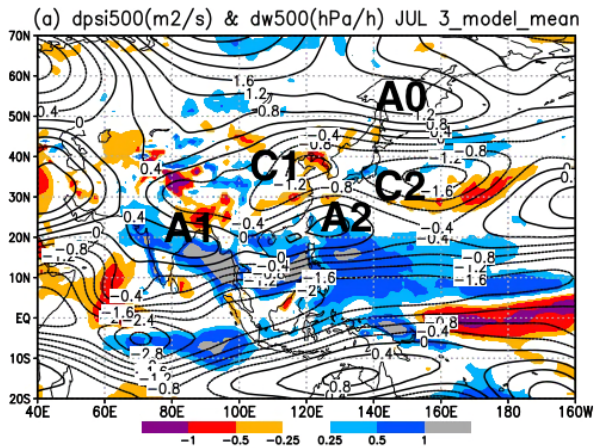

(b) dpsi500 \& dw500(hPo/h) JUL HFA rcp85-HPA
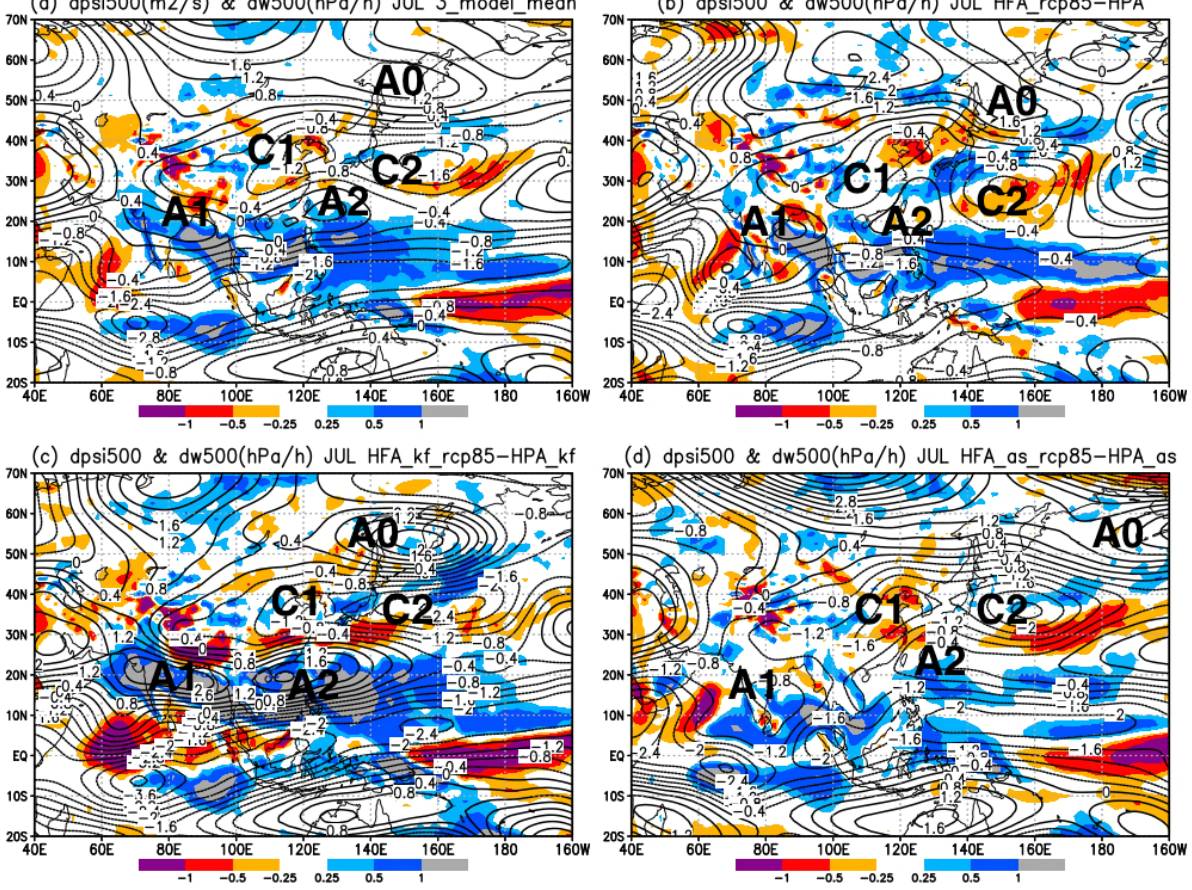

Fig. 11. Projected future changes in the stream function at $500 \mathrm{hPa}\left(10^{6} \mathrm{~m}^{2} \mathrm{~s}^{-1}\right)$ for July (contours). Contour intervals are $0.4 \mathrm{~m}^{2} \mathrm{~s}^{-1} . \mathrm{C} 1$ and $\mathrm{C} 2$ denote cyclonic circulation anomalies, whereas A0, A1, and A2 are anticyclonic circulation anomalies. The shading represents projected changes in vertical velocity in the pressure coordinate $\left(\mathrm{hPa} \mathrm{h}^{-1}\right)$. Values are shown for the (a) three-model ensemble mean, (b) YS model, (c) KF model, and (d) AS model.
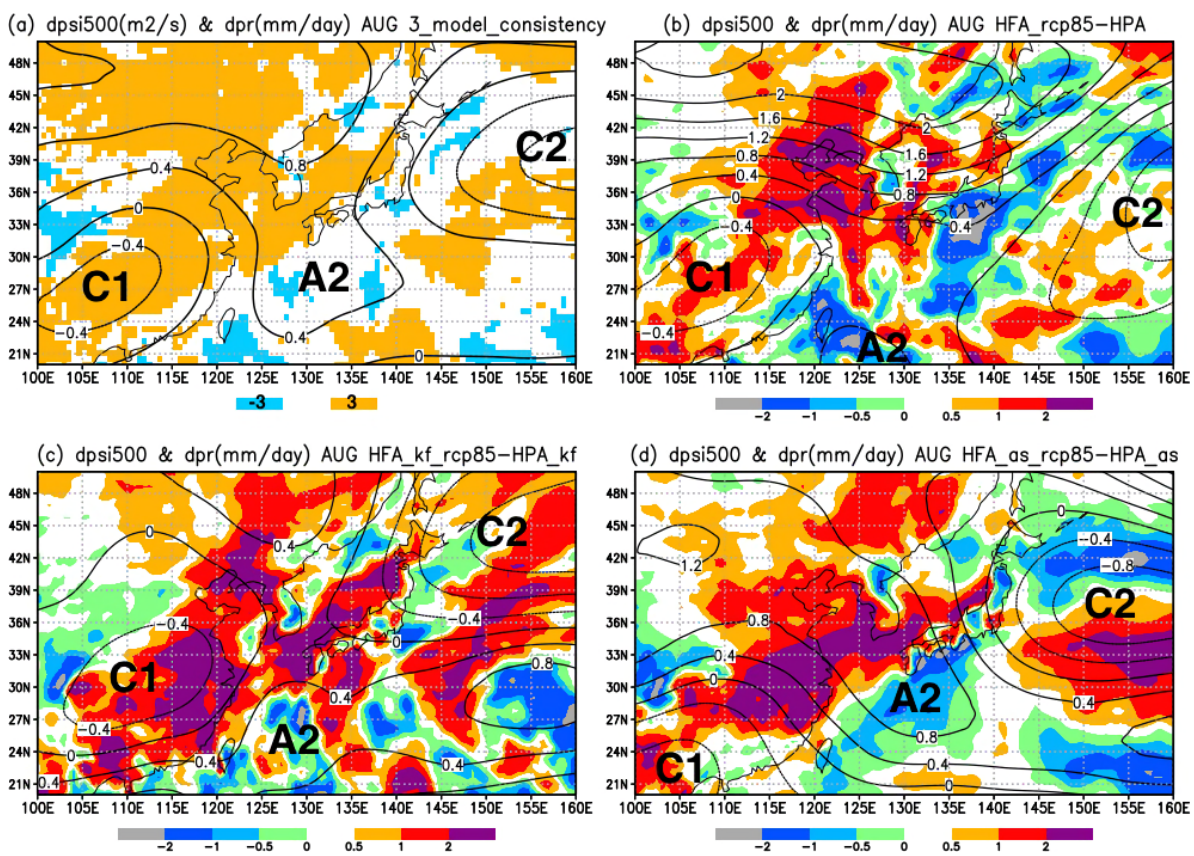

Fig. 12. Same as Fig. 9 but for August. 


\section{Discussion}

\subsection{Relationship between $C 1, C 2$, and the Asia-Pacific monsoon circulation}

$\mathrm{C} 1$ and $\mathrm{C} 2$ are key characteristics of future changes in atmospheric circulation at $500 \mathrm{hPa}$, influencing future precipitation in East Asia. As the loci of both patterns are simulated to shift between June and August (Fig. 8), it is crucial to establish how $\mathrm{C} 1$ and $\mathrm{C} 2$ relate to the present-day seasonal evolution of atmospheric circulation to better understand future precipitation.

Figure 13 shows the $500 \mathrm{hPa}$ zonal-wind velocity simulated for the present day and future (color), together with the observed climatology. According to the observed JJA mean (Fig. 13a), East Asia experiences two major westerly jets: one stretching from Japan to the western North Pacific and a second centered over the continent itself. Comparing the observed and simulated $8 \mathrm{~m} \mathrm{~s}^{-1}$ contour data, these midlatitude jets are reproduced well in the threemodel-mean present-day climatology. The observed westerly domain corresponding to the lower-level westerly jet of the South Asian monsoon, which is located north of the equator in the Indian Ocean, is also well simulated. The three-model mean simulates the observed easterly air flow over the northern Arabian Sea, which extends eastward along the northern part of South Asia to the Pacific.

In the present-day simulation and observation in Fig. 13b, the Pacific westerly jet is located south of Japan in June, but it is shifted southward in future climate, which is represented by $\mathrm{C} 2$ in Fig. $8 \mathrm{~b}$ or Fig. 14b. The continental jet in June also tends to strengthen in the midlatitudes and weaken over the northern continental regions in the future, corresponding to $\mathrm{C} 1$ in Fig. 14b. Both the easterly air flow over northern India and the westerly flow in the Indian Ocean weaken in future climate simulations, reflecting the declining intensity of the South Asian monsoon. Moreover, the simulated future change of westerly tendency (weakened easterly air flow) over northern India is connected to the southern parts of both $\mathrm{C}^{\prime}$ in southern China and $\mathrm{C} 2$ in the western North Pacific (a) $u 500(\mathrm{~m} / \mathrm{s})$ \& du500(m/s) JJA 3_model_mean

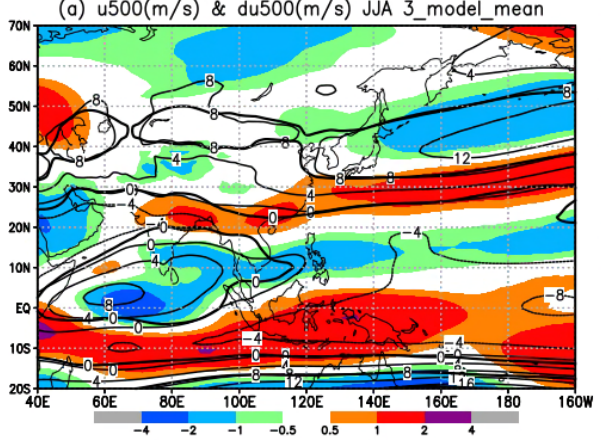

(c) $u 500(\mathrm{~m} / \mathrm{s}) \&$ du $500(\mathrm{~m} / \mathrm{s})$ JUL 3_model_mean

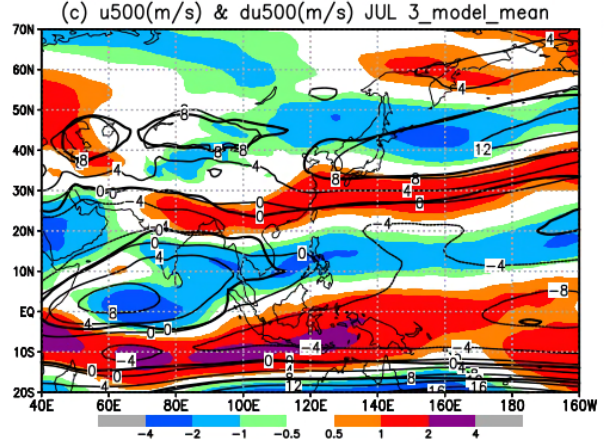

(b) $u 500(\mathrm{~m} / \mathrm{s})$ \& du500(m/s) JUN 3_model_mean

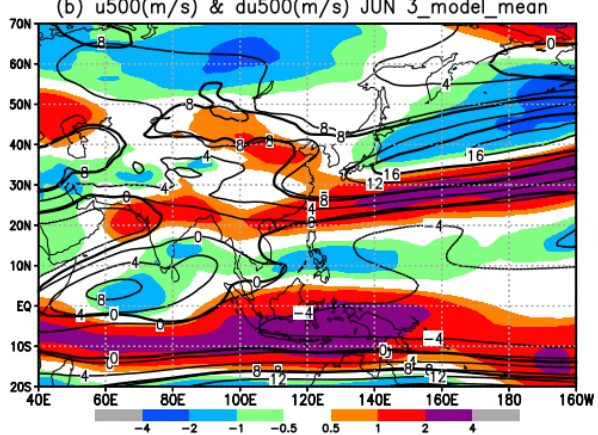

(d) $u 500(\mathrm{~m} / \mathrm{s}) \&$ du $500(\mathrm{~m} / \mathrm{s})$ AUG 3_model_mean

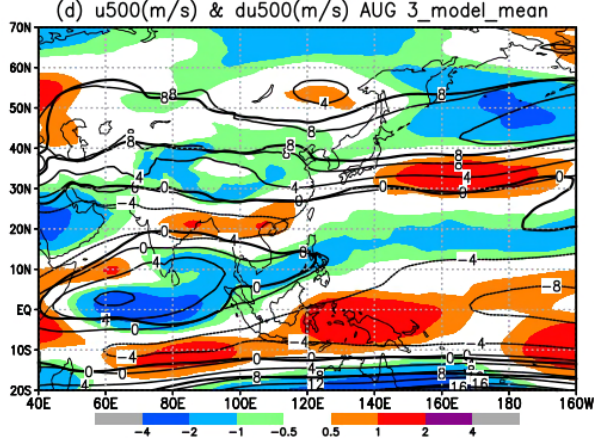

Fig. 13. Projected future changes in the three-model ensemble 25 -year mean of $500 \mathrm{hPa}$ zonal-wind velocity over East Asia from the period 1980-2004 to 2075-2099. Values are shown for (a) the JJA average, (b) June, (c) July, and (d) August (shading). The thin/thick contours represent the present-day climatology simulations/observations by JRA-55. All units are in $\mathrm{m} \mathrm{s}^{-1}$. The contour intervals are every $4 \mathrm{~m} \mathrm{~s}^{-1}$ for the simulations and $8 \mathrm{~m} \mathrm{~s}^{-1}$ for the observations. 
(a) dpsi500(m2/s) \& dw500(hPa/h) JJA 3 model mean

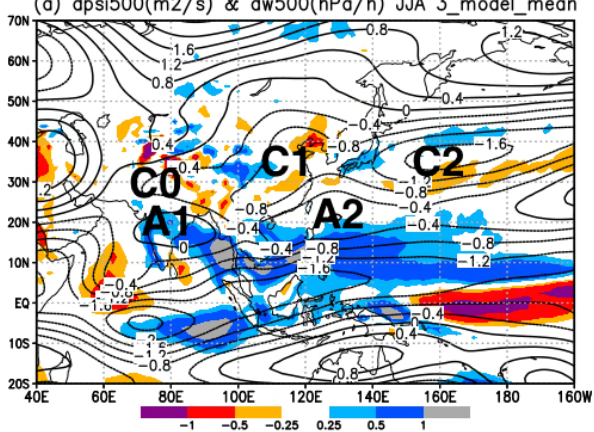

(c) dpsi500(m2/s) \& dw500(hPa/h) JUL 3 model mean

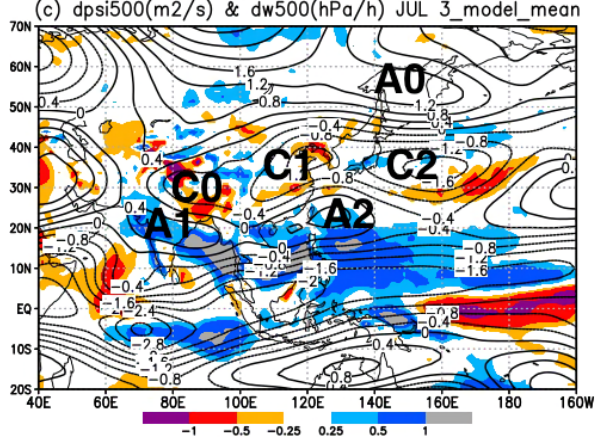

(b) dpsi500(m2/s) \& dw500(hPa/h) JUN 3_model_mean

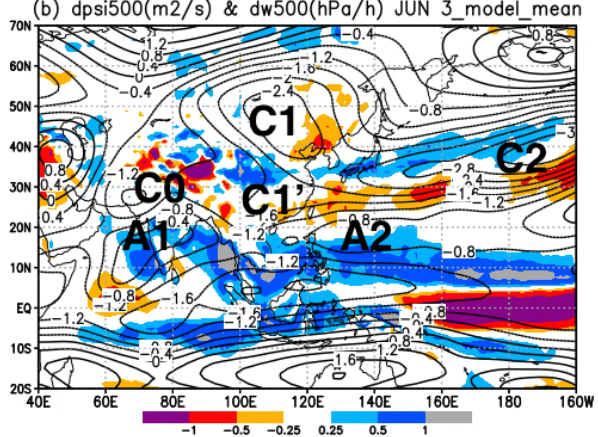

(d) $\mathrm{dpsi} 500(\mathrm{~m} 2 / \mathrm{s}) \& \mathrm{dw} 500(\mathrm{hPa} / \mathrm{h})$ AUG 3 model mean

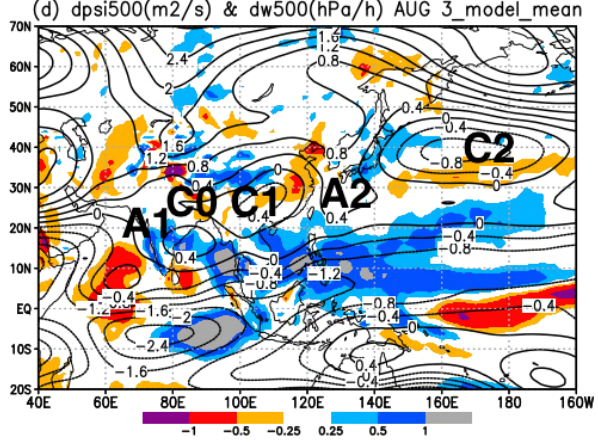

Fig. 14. Same as Fig.11 but for the three-model ensemble mean in (a) the JJA average, (b) June, (c) July, and (d) August. C1, C1', and C2 denote cyclonic circulation anomalies, whereas A0, A1, and A2 are anticyclonic circulation anomalies.

(Fig. 14b).

Compared with the present-day June climatology, the Pacific jet in present-day July is weak and is located slightly to the north (Fig. 13c). In future climate simulations, the jet shifts southward and forms $\mathrm{C} 2$ at a marginally higher latitude than that in June. Concurrently, the future deceleration of the northern part of the Pacific westerly jet extends west toward the continental jet, forming $\mathrm{C} 1$ over eastern to southern China (Fig. 8c). The Pacific jet moves farther north during August and merges with the strengthened continental jet (Fig. 13d). The projected C2 extension, which indicates a southward shift of the Pacific jet under future conditions, is limited east of Japan, in contrast to June and July projections (Fig. 8d). The westerly and easterly air flows centered over southern China and South Asia, respectively, are simulated to weaken in the future, leading to the formation of the August C1 (Fig. 14d).

The projected $\mathrm{C} 2$ seems to be the diminished northward migration of Asia-Pacific monsoon circulation (Fig. 14). This feature is consistent with diagnostics of the delayed northward migration of the upper-level Pacific jet (Fig. 15). C2 can be regarded as a manifes- tation of the weakened Asia-Pacific monsoon circulation, as suggested by Hirahara et al. (2012).

In contrast, the development of $\mathrm{C} 1$ in future simulations indicates cyclonic circulation anomalies over the eastern continent, a pattern that changes its location to southern regions over the course of the summer (Fig. 14). Projected changes in the $200 \mathrm{hPa}$ midlatitude jet over the eastern continent, are simply a southward shift from the present-day position, which are similar to the changes in the jet over the western North Pacific (Fig. 15). Although the future changes in upper-level and lower-level circulations (Figs. 15, 16) in the midlatitudes are basically cyclonic and consistent with $\mathrm{C} 1$ (Fig. 14), the $\mathrm{C} 1$ pattern seems to be more similar to the lower-level circulation pattern than to the upper-level circulation, especially for August. For southern regions, $\mathrm{C}^{\prime}$ in June and $\mathrm{C} 1$ in July and August share a southerly wind component with A2. The development of the $\mathrm{A} 1$ and $\mathrm{A} 2$ patterns at $500 \mathrm{hPa}$ over South Asia, depicted in Fig. 14, is related to the lower-level circulation of a weakened South Asian monsoon such as the weakening of climatological westerly jet, heat-low and even precipitation in South Asia (Fig. 16). These can be regarded as a response 
(a) dpsi200(m2/s) \& U200(m/s) JJA 3 model mean

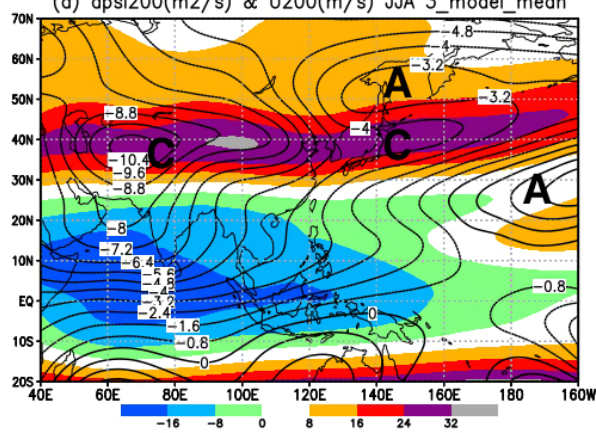

(c) dpsi200(m2/s) \& U200(m/s) JUL 3_model_mean

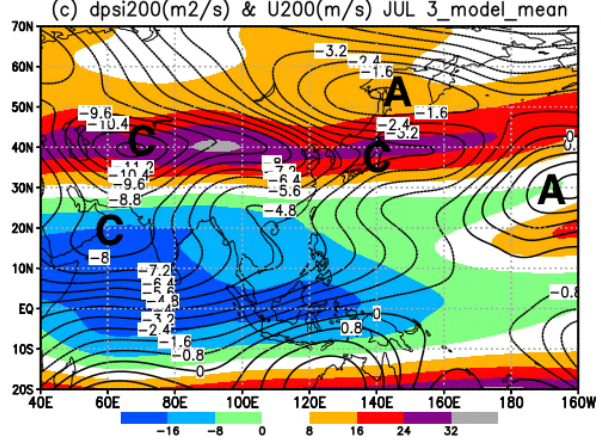

(b) $\mathrm{dpsi} 200(\mathrm{~m} 2 / \mathrm{s})$ \& U $200(\mathrm{~m} / \mathrm{s})$ JUN 3 model mean

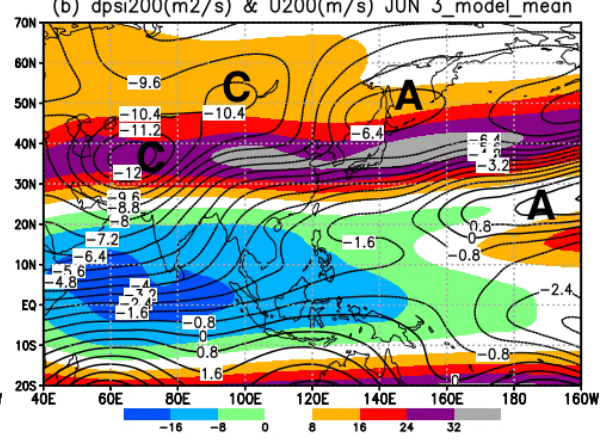

(d) $\mathrm{dpsi200}(\mathrm{m} 2 / \mathrm{s}) \& \mathrm{U} 200(\mathrm{~m} / \mathrm{s})$ AUG 3 model mean

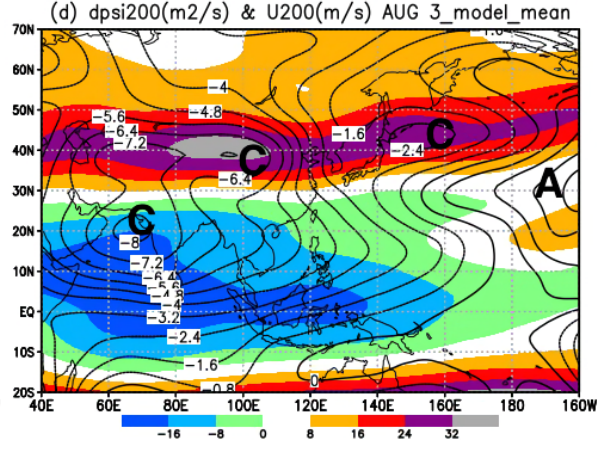

Fig. 15. Same as Fig. 14 except for the future change in the stream function at $200 \mathrm{hPa}$ (contours with intervals of $0.8 \mathrm{~m}^{2} \mathrm{~s}^{-1}$ ) and the present-day climatological zonal wind at $200 \mathrm{hPa}$ (shadings). The units for zonal wind are $\mathrm{m} \mathrm{s}^{-1}$. $\mathrm{C}$ denotes cyclonic circulation anomalies, whereas $\mathrm{A}$ is anticyclonic circulation anomalies.

to suppressed tropical uplift under future conditions (Fig. 14).

Interestingly, cyclonic circulation anomalies $\mathrm{C}$, seemingly a heat low in the future changes, are found at $500 \mathrm{hPa}$ over the Tibetan Plateau and high lands in the north of A1 (Fig. 14). The projected westerlies between $\mathrm{C} 0$ and $\mathrm{A} 1$ are accompanied by an increase of upward motion and precipitation over northeastern South Asia (Figs. 14, 16). Similarly, C1 and C1' during June to August may be formed by increased land surface temperatures under global warming summer, which are larger than those over the oceans (Endo et al. 2018).

Asia-Pacific monsoons are affected by global warming through many processes, such as land-ocean heat contrast, SST distribution, and convective activity (e.g., Endo et al. 2018; Ose and Arakawa 2011). Therefore, future changes in Asia-Pacific monsoons are not necessarily similar to their interannual variations or to their seasonal changes. How to describe the future changes in Asia-Pacific monsoons may be dependent on their definitions. The projected southerly winds at the upper level of East Asia (Fig. 15) are against the present-day climatological northerly winds.
This fact clearly indicates weakened Asia-Pacific monsoons in East Asia in view of meridional winds in East Asia. The future change toward northerly winds over the ocean at the lower level of East Asia (Fig. 16) is a reverse of present-day climatological southerly winds, also indicating weakened Asia-Pacific monsoons. However, the strengthened southerly winds are projected over some regions of the eastern continent at the lower level (Fig. 16), suggesting strengthened Asia-Pacific monsoons.

In summary, while the projected $\mathrm{C} 2$ seems to be consistent with the delayed northward migration of the upper-level Pacific jet (Fig. 15), C1 is more similar to the future change in the lower-level circulation (Fig. 16) than in the upper-level one (Fig. 15). An inference is that the southerly wind zone of $\mathrm{C} 1$ is part of the low-level strengthened monsoon circulation over the eastern continent, whereas the northerly wind zone of $\mathrm{C} 2$ reflects the weakened Asia-Pacific monsoon circulation over the western North Pacific.

\subsection{Differences among the models in projections of future precipitation}

While the model-dependent positions and exten- 

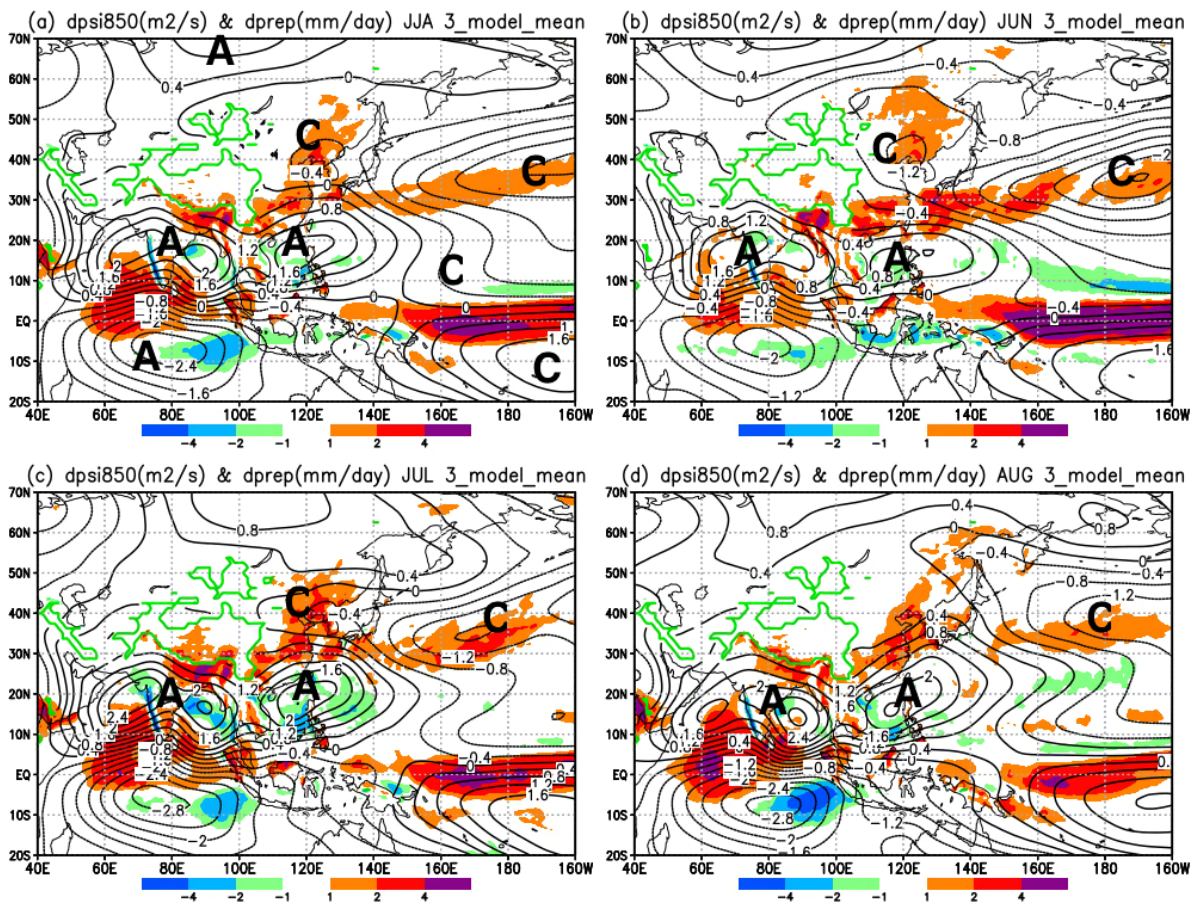

Fig. 16. Same as Fig. 14 except for the future changes in the stream function at $850 \mathrm{hPa}$ (black contours) and precipitation (shadings). The units for precipitation are $\mathrm{mm}^{-1 a y}{ }^{-1}$. Green contours indicate high lands over $850 \mathrm{hPa}$ level. $\mathrm{C}$ denotes cyclonic circulation anomalies, whereas $\mathrm{A}$ is anticyclonic circulation anomalies.

sions of $\mathrm{C} 1$ and $\mathrm{C} 2$ give rise to clear inconsistencies among projections of monthly mean precipitation over Japan, such discrepancies are not evident over the eastern continental regions, as described above. The principal reason for this difference is that anticipated changes in Japanese precipitation are highly sensitive to the effects of $\mathrm{C} 2$, which tend to cancel the "wet-getwetter" effect.

Future atmospheric conditions in detail, such as magnitude and locations of $\mathrm{C} 1$ and $\mathrm{C} 2$, are apparently uncertain because of many unknown processes involved in future changes, compared with the present-day climatology simulations to be confirmed in modeling processes and the moisture increase in future warmer climatology. For example, the YS-simulated movement of C2 during June to July is contrary to the simple northward shift predicted by the ensemble mean (Figs. 9, 10). While it might be possible to explore the cause of such inconsistencies, this does not necessarily lead to the identification of the most appropriate model for projecting future climate. Furthermore, any assessment of anticipated atmospheric circulation must include uncertainty due to future SST changes and interannual atmospheric variability.

\section{Summary}

Global warming simulations undertaken using MRI-AGCM3.2H provide the basis for estimating likely changes in monthly summer (June to August) precipitation over East Asia. The common qualitative characteristics of projected monthly precipitation were assessed by analyzing the three-model ensemble of the YS, KF, and AS cumulus schemes. Rather than focusing on the statistical significance of output and model reliability, the objective of this study was to provide a refined understanding and qualified explanation of future summer precipitation changes, as such understanding may be useful in assessing the findings of subsequent model runs. The main conclusions are summarized as follows.

The general features of projected changes in summer precipitation in East Asia are summarized as follows:

- The wet and dry effects related to projected changes in mean vertical motion, as well as the "wet-getwetter" effect driven by an overall increase in moisture, are fundamental processes in the simulations of future precipitation patterns over East Asia.

- Future changes in the mean vertical motion are 
attributable to those of the mean adiabatic vertical motion, as estimated from 25-year monthly average horizontal circulation at $500 \mathrm{hPa}$. This result is consistent with the study of Ose (2017) based on Sampe and Xie (2010).

- Over Japan, summer precipitation is projected to decrease in response to downward-motion tendency, which tends to cancel out the "wet-get-wetter" effect in the present-day Baiu region. This offset process leads to a large uncertainty due to model dependence, concerning whether precipitation increases or decreases regionally. For the regions of Japan dominated by both the "wet-get-wetter" effect and an anticipated change toward upward (or weak) motion, all three models predict an overall increase in precipitation consistently.

- Over the majority of continental East Asia, summertime precipitation is projected to increase in response to both the upward-motion tendency and the "wet-get-wetter" effect, as well as the increased evaporation.

Summaries for future changes in monthly summertime atmospheric circulation over East Asia are given as follows:

- The simulated future changes of horizontal atmospheric circulation at $500 \mathrm{hPa}$ are characterized by two cyclonic circulation anomalies: one oriented north-south over the eastern continent (C1) and the other extending east-west over the western North Pacific Ocean (C2). By comparison to the presentday climatology, it is inferred that the southerly wind zone of $\mathrm{C} 1$ is part of the low-level strengthened monsoon circulation over the eastern continent in East Asia, whereas C2, indicating the delayed migration of the Pacific jet and northerly air flow in East Asia, reflects the weakened Asia-Pacific monsoon circulation over the western North Pacific under global warming conditions.

- Between June and August, the western edge of C2 shifts from a position south of Japan to northernmost Japan, representing delayed northward migration or southward shift of the westerly jet over the western North Pacific. Most regions of Japan are impacted by the northerly air flow of $\mathrm{C} 2$ during the summer months, indicating drier effects due to the downward-motion tendency in Japan against the "wet-get-wetter" effect in East Asia.

- C1 distributes over northeastern China in June and central and southern China in July and August, respectively. $\mathrm{C} 1$ appears to be more closely related to projected changes in the lower circulation $(850 \mathrm{hPa})$ than the upper westerly jet $(200 \mathrm{hPa})$. As most eastern continental regions are located in the southerly wind zone of $\mathrm{C} 1$ during the summer, future conditions are likely to include the upward-motion tendency, indicating increased precipitation.

The projected monthly precipitation changes over Japan are summed up as follows:

- During June, C2 is simulated to expand eastward from a position south of Japan, indicating a likely southward shift of the westerly jet and Baiu precipitation in future years. While this process may result in decreased precipitation in central Japan, precipitation is projected to increase over southern Japan via the "wet-get-wetter" effect, particularly pronounced over the Southwest Islands with the help of the C2-derived southward shift of the Baiu.

- The eastward expansion of C2 during July, from its locus over central Japan, suggests a possible future decrease in precipitation over parts of central Japan, whereas the "wet-get-wetter" effect serves to increase precipitation in the northern area and Pacific side of the archipelago. Furthermore, the positioning of $\mathrm{C} 1$ over central China also tends to enhance precipitation over the Southwest Islands and western Japan, in addition to parts of northern Japan.

- During August, a dry effect related to the downward-motion area of $\mathrm{C} 2$ drives a decrease in precipitation on the Pacific margin of Japan in the future. However, this process is restricted to eastern Japan, whereas western Japan and possibly the Japan Sea side of Japan are projected to experience increased precipitation under the "wet-get-wetter" effect.

The monthly precipitation changes over the eastern continent are summarized as follows:

- In June, the "wet-get-wetter" effect is projected to impact the present-day Meiyu region of southern China, whereas the "dry-get-drier" effect will likely influence northern China. Combined with the wet effect of $\mathrm{Cl}^{\prime}$ centered over southern China, precipitation is projected to increase significantly there in future years. Consequently, the upward- and downward-motion tendencies of $\mathrm{C} 1$ produce contrasting wet and possible dry conditions over northeastern and central-interior China, respectively.

- In July, while the "wet-get-wetter" effect appears over northeastern China, central China, and Korea following the present-day precipitation pattern in July, the "dry-get-drier" effect exists but weakens over northern China. The upward-motion tendency 
of $\mathrm{C} 1$ contributes to wetter future climatology in northern China. Ultimately, a general increase in precipitation is anticipated from northeastern China to central China and Korea.

- During August, the general weakening of the "wetget-wetter" effect over the eastern continent is countered by sustained upward motion east of $\mathrm{C} 1$ in central China, so that a general increase in precipitation is projected from northeastern China to central China and Korea.

This study was conducted using three versions of MRI-AGCM with different cumulus schemes, in order to exploit their high resolution and demonstrated efficacy for simulating present-day conditions over East Asia. The three models produce a high degree of consistency among their respective simulations of future precipitation and atmospheric circulation under global warming conditions. Nonetheless, those may not have enough diversity in model performances. In atmosphere-ocean coupling, it is possible that daily SST fluctuations influence convective precipitation, which is not considered in the MRI-AGCM simulations. Therefore, comparative studies of projected global warming impacts using, for example, CMIP5 and the forthcoming sixth phase of CMIP (CMIP6), are warranted, although much attention should be paid to the realization of simulated SST fluctuations as well as their present-day climatology simulations.

\section{Acknowledgments}

This work was supported by the Theme-C Integrated Research Program for Advancing Climate Models (TOUGOU) of the Ministry of Education, Culture, Sports, Science, and Technology (MEXT) of Japan.

\section{References}

Adler, R. F., G. J. Huffman, A. Chang, R. Ferraro, P.-P. Xie, J. Janowiak, B. Rudolf, U. Schneider, S. Curtis, D. Bolvin, A. Gruber, J. Susskind, P. Arkin, and E. Nelkin, 2003: The version-2 Global Precipitation Climatology Project (GPCP) monthly precipitation analysis (1979-present). J. Hydrometeor, 4, 1147-1167.

Emori, S., and S. J. Brown, 2005: Dynamic and thermodynamic changes in mean and extreme precipitation under changed climate. Geophys. Res. Lett., 32, L17706, doi:10.1029/2005GL023272.

Endo, H., 2012: Future changes of Yamase bringing unusually cold summers over northeastern Japan in CMIP3 multi-models. J. Meteor. Soc. Japan, 90A, 123-136.

Endo, H., and A. Kitoh, 2014: Thermodynamic and dynamic effects on regional monsoon rainfall changes in a warmer climate. Geophys. Res. Lett., 41, 1704-1710.
Endo, H., A. Kitoh, T. Ose, R. Mizuta, and S. Kusunoki, 2012: Future changes and uncertainties in Asian precipitation simulated by multiphysics and multi-sea surface temperature ensemble experiments with highresolution Meteorological Research Institute atmospheric general circulation models (MRI-AGCMs). J. Geophys. Res., 117, D16118, doi:10.1029/2012JD 017874.

Endo, H., A. Kitoh, and H. Ueda, 2018: A unique feature of the Asian summer monsoon response to global warming: The role of different land-sea thermal contrast change between the lower and upper troposphere. SOLA, 14, 57-63.

Held, I. M., and B. J. Soden, 2006: Robust responses of the hydrological cycle to global warming. J. Climate, 19, 5686-5699.

Hirahara, S., H. Ohno, Y. Oikawa, and S. Maeda, 2012: Strengthening of the southern side of the jet stream and delayed withdrawal of Baiu season in future climate. $J$. Meteor. Soc. Japan, 90, 663-671.

Horinouchi, T., and A. Hayashi, 2017: Meandering subtropical jet and precipitation over summertime East Asia and the northwestern Pacific. J. Atmos. Sci., 74, 12331247.

IPCC, 2013: Climate Change 2013: The Physical Science Basis. Contribution of Working Group I to the Fifth Assessment Report of the Intergovermental Panel on Climate Change. Stocker, T. F., D. Qin, G. K. Plattner, M. M. B. Tignor, S. K. Allen, J. Boschung, A. Nauels, Y. Xia, V. Bex, and R. M. Midgley (eds.), Cambridge University Press, Cambridge, 1535 pp.

Japan Meteorological Agency, 2007: Outline of the operational numerical weather prediction at the Japan Meteorological Agency. Appendix to WMO numerical weather prediction progress report. $194 \mathrm{pp}$.

Kain, J. S., and J. M. Fritsch, 1990: A one-dimensional entraining/detraining plume model and its application in convective parameterization. J. Atmos. Sci., 47, 2784-2802.

Kamae, Y., M. Watanabe, M. Kimoto, and H. Shiogama, 2014: Summertime land-sea thermal contrast and atmospheric circulation over East Asia in a warming climate - Part I: Past changes and future projections. Climate Dyn., 43, 2553-2568.

Kimoto, M., 2005: Simulated change of the east Asian circulation under global warming scenario. Geophys. Res. Lett., 32, L16701, doi:10.1029/2005GL023383.

Kitoh, A., and T. Uchiyama, 2006: Changes in onset and withdrawal of the East Asian summer rainy season by multi-model global warming experiments. J. Meteor. Soc. Japan, 84, 247-258.

Kitoh, A., S. Yukimoto, A. Noda, and T. Motoi, 1997: Simulated changes in the Asian summer monsoon at times of increased atmospheric $\mathrm{CO}_{2}$. J. Meteor. Soc. Japan, 75, 1019-1031.

Kitoh, A., T. Ose, and I. Takayabu, 2016: Dynamical down- 
scaling for climate projection with high-resolution MRI AGCM-RCM. J. Meteor. Soc. Japan, 94A, 1-16.

Kobayashi, S., Y. Ota, Y. Harada, A. Ebita, M. Moriya, H. Onoda, K. Onogi, H. Kamahori, C. Kobayashi, H. Endo, K. Miyaoka, and K. Takahashi, 2015: The JRA-55 Reanalysis: General specifications and basic characteristics. J. Meteor. Soc. Japan, 93, 5-48.

Kusunoki, S., 2016: Is the global atmospheric model MRI-AGCM3.2 better than the CMIP5 atmospheric models in simulating precipitation over East Asia? Climate Dyn., 51, 4489-4510.

Kusunoki, S., 2017: Future changes in precipitation over East Asia projected by the global atmospheric model MRI-AGCM3.2. Climate Dyn., 51, 4601-4617.

Mizuta, R., H. Yoshimura, H. Murakami, M. Matsueda, H. Endo, T. Ose, K. Kamiguchi, M. Hosaka, M. Sugi, S. Yukimoto, S. Kusunoki, and A. Kitoh, 2012: Climate simulations using MRI-AGCM3.2 with 20-km grid. $J$. Meteor. Soc. Japan, 90A, 233-258.

Mizuta, R., O. Arakawa, T. Ose, S. Kusunoki, H. Endo, and A. Kitoh, 2014: Classification of CMIP5 future climate responses by the tropical sea surface temperature changes. SOLA, 10, 167-171.

Okada, Y., T. Takemi, H. Ishikawa, S. Kusunoki, and R. Mizuta, 2017: Future changes in atmospheric conditions for the seasonal evolution of the Baiu as revealed from projected AGCM experiments. J. Meteor. Soc. Japan, 95, 239-260.

Ose, T., 2017: Future precipitation changes during summer in East Asia and model dependence in high-resolution MRI-AGCM experiments. Hydrol. Res. Lett., 11, 168-174.

Ose, T., and O. Arakawa, 2011: Uncertainty of future precip- itation change due to global warming associated with sea surface temperature change in the tropical Pacific. J. Meteor. Soc. Japan, 89, 539-552.

Pan, D.-M., and D. A. Randall, 1998: A cumulus parameterization with a prognostic closure. Quart. J. Roy. Meteor. Soc., 124, 949-981.

Sampe, T., and S.-P. Xie, 2010: Large-scale dynamics of the Meiyu-baiu rainband: Environmental forcing by the westerly jet. J. Climate, 23, 113-134.

Seager, R., N. Naik, and G. A. Vecchi, 2010: Thermodynamic and dynamic mechanisms for large-scale changes in the hydrological cycle in response to global warming. J. Climate, 23, 4651-4668.

Tiedtke, M., 1989: A comprehensive mass flux scheme for cumulus parameterization in large-scale models. Mon. Wea. Rev., 117, 1779-1800.

Vecchi, G. A., and B. J. Soden, 2007: Global warming and the weakening of the tropical circulation. J. Climate, 20, 4316-4340.

Wang, Y., and T. Yasunari, 1994: A diagnostic analysis of the wave train propagating from high-latitudes to lowlatitudes in early summer. J. Meteor. Soc. Japan, 72, 269-279.

Yoshimura, H., R. Mizuta, and H. Murakami, 2015: A spectral cumulus parameterization scheme interpolating between two convective updrafts with semiLagrangian calculation of transport by compensatory subsidence. Mon. Wea. Rev., 143, 597-621.

Zhou, S., G. Huang, and P. Huang, 2018: Changes in the East Asian summer monsoon rainfall under global warming: Moisture budget decomposition and the sources of uncertainty. Climate Dyn., 51, 1363-1373. 